\title{
Prediction of compression strength of ancient mortars through in situ drilling resistance technique
}

\author{
Emanuele Del Monte ${ }^{1}$, Sonia Boschi ${ }^{*, 2}$, Andrea Vignoli \\ Department of Civil and Environmental Engineering, University of Florence, Via di Santa Marta, 3, 50139 Florence, Italy
}

\section{H I G H L I G H T S}

- Extensive in laboratory experimental campaign on low-strength mortars.

- Correlations among the DRMS mode and average values and the mortars' compressive strength.

- Definition of a stepwise process to apply to the mortar joints of existing buildings.

- Reliability of the proposed procedure proved by in situ applications.

\section{A R T I C L E I N F O}

\section{Article history:}

Received 18 July 2019

Received in revised form 22 October 2019

Accepted 8 November 2019

\section{Keywords:}

Low-strength mortars

In situ tests

Minor Destructive Testing

Compressive strength

Drilling resistance

DRMS test

\begin{abstract}
A B S T R A C T
The paper presents the results of a research project carried out to determine the mechanical characteristics of mortar in historical masonry buildings by drilling resistance technique (DRMS).

A set of mortar mixtures have been produced in experimental campaigns covering different compressive strengths typical of historic mortars. The mortars have been obtained with different classes of binder and river sand with different grading curves. Specimens obtained were subjected both to flexural, compression and DRMS laboratory tests.

Considering the results of the drilling measurement distributions, both the mode and the average value, the latter obtained after a statistical treatment in which extreme outliers are deleted, have been taken as reference values for each test performed. Effective correlations between the mode and average values of DRMS tests and the compressive strengths of the mortars are provided.

Finally, a stepwise process to be followed for in situ use of DRMS is defined and applied to mortar joints of some existing masonry buildings in Tuscany (Italy).
\end{abstract}

(C) 2019 Elsevier Ltd. All rights reserved.

\section{Introduction}

Recent Italian seismic events have once again highlighted the vulnerability of the historical masonry building heritage. One of

Abbreviations: CS, Case Study; CV, coefficient of variation; DRMS, Drilling Resistance Measurement System; DR, force measured by the DRMS test; $\mathrm{DR}_{\mathrm{av}}$, average of the DRMS values; $\mathrm{DR}_{\mathrm{i}}$, force measured by the DRMS test using a generic i-drill bit; $\mathrm{DR}_{\text {mo }}$, mode of the DRMS values; MDT, Minor Destructive Testing; NC, Natural Cement (PROMPT type); NHL, Natural Hydraulic Lime; NDT, Non-Destructive Testing; PC 32.5, Portland Cement Type II/B-LL 32.5 R; $R_{C}$ compressive strength of the mortar; SK, Skewness; SL, slaked lime (CL 80-S); StD, standard deviation; $v$, penetration rate; $\omega$, revolution speed.

* Corresponding author.

E-mail addresses: emadelmo@dicea.unifi.it (E. Del Monte), sonia.boschi@unifi.it (S. Boschi), andrea.vignoli@unifi.it (A. Vignoli).

1 ORCID: 0000-0002-2861-3648.

2 ORCID: 0000-0001-5175-2905. the causes of the high vulnerability is the poverty of materials especially the mortar used in buildings of the rural historical centres [1-3].

The structural evaluation of historic buildings has become a necessary step to be taken to prevent the seismic risk and to preserve the historical and artistic heritage (some examples in [4-8]). When analysing a historical construction, the evaluation of the mechanical characteristics of the materials is one of the major issues to be addressed. Although destructive in situ tests allow the direct estimation of the mechanical characteristics of the masonry types, they usually have to be excluded due to their high cost and impact on the monumental constructions [9]. Therefore, tests on the components - namely stones, blocks and mortar - have to be done, from which it is possible to derive the characteristics of the masonry. All national $[10,11]$ and international [12] standards indeed, define the parameters of masonry types, such as the compression and shear strengths, depending 
on the mechanical properties of the elements. In the new buildings, this method has no difficulties. In the existing buildings, the compression tests on stones are possible on samples directly extracted from buildings [13]; for mortars in situ tests are necessary. Physical methods, chemical methods and petrographic section analysis, all examples of Not Destructive Testing (NDT), have been codified in the Standards, but they only provide qualitative information (binder and aggregate types and their relative ratios).

Recently, a series of in situ Minor Destructive Testing (MDT) to obtain information about the main characteristics of the ancient mortars have been studied. The principal goals refer to $i$ ) numerically evaluate of the compressive strength of the mortar (understanding if the mortar has good quality [15-17]) and ii) evaluate the consolidation action of any treatment on a soft-strength mortars [14].

MDTs on mortar can be grouped among different penetrometric, percussion and rotation techniques carried out on mortar joints directly in situ or on small samples extracted from the masonry [18-20]. Focusing on in situ investigation techniques, different types of static penetrometers have been developed [21,22]. Starting by the basic principle of the penetration tests used in soil characterization, the instrument consists of a metal pin that is driven into the mortar. The recorded penetration depth of the pin is correlated to the compressive strength of the mortar. Gucci and Barsotti [23], instead, proposed a hand drill able to correlate the energy required to drill a small cavity in the mortar layer to the local compressive resistance of the mortar.

Among percussion techniques, the rebound hammer is ordinarily used in reinforced concrete testing to determine the compressive strength of the hardened concrete and its uniformity [24,25]. Different versions of the instrument have been developed for mortar elements [26] to correlate the compressive strength of the mortar and its superficial hardness. Those proposed by Van Der Klugt [27] or Schmiedmayer [28] are some examples.

Christiansen [29] proposed a torque penetrometer (X-Drill) consisting of a four-teeth nail made of stainless steel to be driven in the mortar joints in a $6 \mathrm{~mm}$-diameter pilot hole. The maximum torque resisted by the mortar is measured and correlated with the compressive strength of some mortars' types. An implementation of this technique has been developed by Marastoni et al. [30,31] presenting a penetrometric tool, called Torque Penetrometric Tests, TPT. They reinterpreted the TPT results based on fracture mechanics theory allowing the evaluation of the compressive strength of existing mortars.

The Drilling Resistance Measurement System (DRMS) is the device that performs the drilling and measures the force to the perforation of the material that is tested, along the drilling depth, keeping stable penetration rate $(v)$ and revolution speed $(\omega)$. Its first application regards stones (for which prediction models of the compressive strength have been attempted, i.e. Tiano et al. [32], Theodoridou et al. [33]), while recently it is used for mortars too. Its application on heterogeneous materials is not yet conventionally established due to the irregularity of the drilling profiles obtained: it is still a research argument and many researchers are working on it [34-43]. In particular, the works of Nogueira et al. [41] recently developed predictive models for the definition of the characteristics for low-quality and heterogeneous mortars through correlations among the main statistical indicators of the DRMS results (average, covariance and skewness) and the compressive strength, pointing out the skewness as the most accurate indicator.

In this study, the drilling resistance technique is used to indirectly define the compressive strength of mortars. To achieve this purpose, extensive experimental campaigns have been developed by the Authors in the Structures and Materials Testing Laboratory at the University of Florence. Several mortar mixtures with different characteristics were tested. Specimens obtained for each class of mortar were subjected both to flexural, compression and DRMS laboratory tests.

Based on the analysis of the drilling measurement distributions, both the mode and the average value - obtained after a statistical approach in which extreme outliers are deleted - have been taken as reference values for each test performed. Predictive correlations between the mode and the mean of DRMS and the compressive strength of the mortar are provided and discussed in the paper.

Finally, a stepwise procedure for the in situ application of the DRMS technique on mortar joints is presented and applied on mortars of some existing buildings in Tuscany, proving the accuracy of the proposed correlations.

\section{Materials and experimental campaign}

\subsection{Drilling resistance technique instrumentations and settings}

Drilling resistance instrument was first implemented at the beginning of the 20th century by Hirschwald to study the weak points of the stone surfaces (Fig. 1a, [35]). Recent devices were developed to stones and heterogenic low-strength materials. Since 2000, the DRMS device has been produced by Sint Technology (Fig. 1b). A modern instrument has been fully developed recently, the DRMS Cordless (Fig. 1c), used herein. In DRMS Cordless, the maximum travel span is $50 \mathrm{~mm}$. The drill bit diameter can vary between 3 and $10 \mathrm{~mm}$. The depth resolution could be low if penetration force is recorded every $0.1 \mathrm{~mm}$ of the travel span, high if it is recorded every $0.05 \mathrm{~mm}$. The penetration rate $(v)$ can vary between 1 and $80 \mathrm{~mm} / \mathrm{min}$ and revolution speed $(\omega)$ between 20 and $1000 \mathrm{rpm}$. The maximum achievable load is $100 \mathrm{~N}$ and the resolution is $\pm 1 \mathrm{~N}$.

The optimization of the DRMS response to the variation of the settings parameters, according to the type of material tested, have already been specifically dealt with by various scientific studies. The drilling resistance value is directly proportional to the penetration rate $(v)$ and inversely proportional to the rotational speed $(\omega)$ $[35,36,42]$. According to the literature results, $40 \mathrm{~mm} / \mathrm{min}$ of penetration rate and $300 \mathrm{rpm}$ of revolution speed values were adopted. The choice was a fair compromise between good readability of the results and a minimum gap to the maximum value recordable by the load cell, for the instrument's resolution.

For each mortar mixture at least 20 holes were performed. High depth resolution was chosen, then each hole had 800 values in a depth of $40 \mathrm{~mm}$. Starting from total depth, a central slender range of reference for the analyses $\left[\mathrm{x}_{1}-\mathrm{x}_{2}\right]$, was defined. This was made to avoid interference caused by the initial transient of the drill bit and a possible accumulation of material on the bottom of the hole. This choice allows making as much as the possible homogeneous quality of mortar avoiding the surface of the sample that may suffer varying degrees of maturation.

\subsection{Characteristics of the mortar types}

Prediction models to characterize the compressive strength of ancient mortar with in situ DRMS tests were obtained through two laboratory experimental campaigns carried out in 2008 and in the two-year period of 2016-2018 (Table 1).

For both the experimentations, the mixtures of the mortars were designed in order to be like the ones found in masonry walls of buildings typical of the Tuscany Region (Italy) or apposite to replace ancient mortars in strengthening interventions on them. 


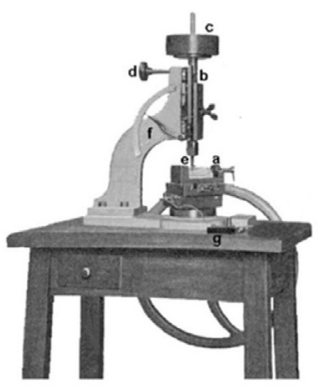

a)

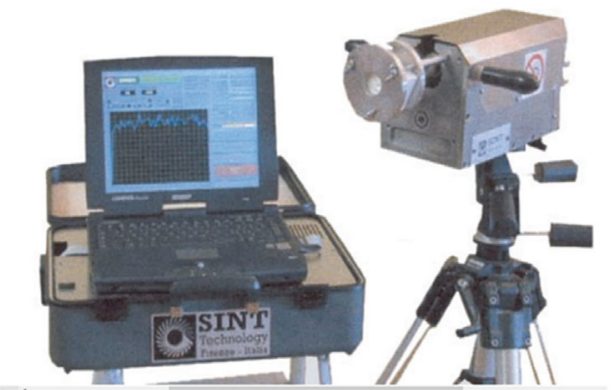

b)

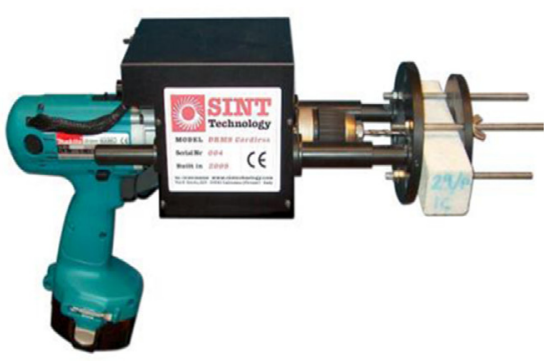

c)

Fig. 1. a) Hirschwald's device [34]); b) SINT Technology DRMS; c) DRMS Cordless [44].

Table 1

Mortar types: physical and mechanical properties from the two campaigns.

\begin{tabular}{|c|c|c|c|c|c|c|c|}
\hline Mortar & Casting date & Binder 1 & Binder 2 & Sand $D^{a}$ & $\mathrm{~B} / \mathrm{A}^{\mathrm{b}}$ & $\mathrm{W} / \mathrm{B}^{\mathrm{c}}$ & $\begin{array}{l}\text { Compressive strength } \\
\mathrm{R}_{\mathrm{C}}\left[\mathrm{N} / \mathrm{mm}^{2}\right]\end{array}$ \\
\hline $\mathrm{A} 1$ & $07 / 2008$ & NHL 5 & - & 1 & $1 / 3$ & 0.85 & 2.98 \\
\hline A4 & $08 / 2008$ & NHL 5 & - & 4 & $1 / 3$ & 0.85 & 2.76 \\
\hline B1 & $07 / 2008$ & NHL 3.5 & - & 1 & $1 / 3$ & 0.85 & 1.88 \\
\hline B4 & $07 / 2008$ & NHL 3.5 & - & 4 & $1 / 3$ & 0.85 & 1.34 \\
\hline $\mathrm{C} 1$ & $08 / 2008$ & NHL 2 & - & 1 & $1 / 3$ & 0.85 & 1.76 \\
\hline $\mathrm{C} 4$ & $09 / 2008$ & NHL 2 & - & 4 & $1 / 3$ & 0.85 & 1.58 \\
\hline D1 & $09 / 2008$ & NHL 5 & - & 1 & $1 / 2$ & 0.66 & 5.17 \\
\hline D4 & $09 / 2008$ & NHL 5 & - & 4 & $1 / 2$ & 0.66 & 5.39 \\
\hline E1 & $09 / 2008$ & NHL 3.5 & - & 1 & $1 / 2$ & 0.66 & 3.82 \\
\hline E4 & $09 / 2008$ & NHL 3.5 & - & 4 & $1 / 2$ & 0.66 & 3.05 \\
\hline $\mathrm{F} 1$ & $09 / 2008$ & NHL 2 & - & 1 & $1 / 2$ & 0.66 & 2.63 \\
\hline F4 & $07 / 2008$ & NHL 2 & - & 4 & $1 / 2$ & 0.66 & 2.05 \\
\hline G1 & $07 / 2008$ & NHL $5(3 / 4)$ & PC $32.5(1 / 4)$ & 1 & $1 / 3$ & 0.70 & 6.74 \\
\hline G4 & $07 / 2008$ & NHL $5(3 / 4)$ & PC $32.5(1 / 4)$ & 4 & $1 / 3$ & 0.75 & 9.24 \\
\hline $\mathrm{H} 1$ & $07 / 2008$ & NHL $3.5(1 / 2)$ & PC $32.5(1 / 2)$ & 1 & $1 / 3$ & 0.70 & 12.80 \\
\hline $1 \mathrm{~N} 3$ & $02 / 2016$ & NHL 3.5 & - & 1 & $1 / 3$ & 0.62 & 2.93 \\
\hline $1 \mathrm{~N} 2$ & $02 / 2016$ & NHL 3.5 & - & 1 & $1 / 2$ & 0.50 & 5.60 \\
\hline $1 \mathrm{~N} 2^{\mathrm{d}}$ & $02 / 2016$ & NHL 3.5 & - & 1 & $1 / 2$ & 0.50 & 7.09 \\
\hline $4 \mathrm{~N} 3$ & $02 / 2016$ & NHL 3.5 & - & 4 & $1 / 3$ & 0.61 & 4.87 \\
\hline $4 \mathrm{~N} 2$ & $02 / 2016$ & NHL 3.5 & - & 4 & $1 / 2$ & 0.56 & 5.56 \\
\hline $1 C 3$ & $02 / 2016$ & - & $\mathrm{NC}$ & 1 & $1 / 3$ & 0.69 & 1.85 \\
\hline $4 C 3$ & $02 / 2016$ & - & $\mathrm{NC}$ & 4 & $1 / 3$ & 0.77 & 3.18 \\
\hline 1CECA3 & $02 / 2016$ & $\operatorname{SL}(1 / 2)$ & $\mathrm{NC}(1 / 2)$ & 4 & $1 / 3$ & 0.73 & 3.56 \\
\hline $1 \mathrm{CACN} 3$ & $03 / 2016$ & NHL $3.5(1 / 2)$ & $\mathrm{SL}(1 / 2)$ & 1 & $1 / 3$ & 0.80 & 2.81 \\
\hline $1 \mathrm{CACN}^{\mathrm{e}}$ & $03 / 2016$ & NHL $3.5(1 / 2)$ & SL $(1 / 2)$ & 1 & $1 / 3$ & 0.80 & 2.70 \\
\hline 4CACN3 & $03 / 2016$ & NHL $3.5(1 / 2)$ & $\operatorname{SL}(1 / 2)$ & 4 & $1 / 3$ & 0.80 & 3.51 \\
\hline
\end{tabular}

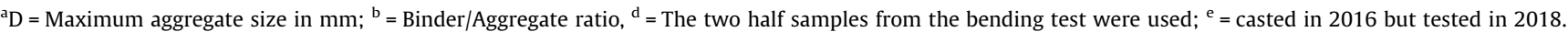

In the first campaign, a set of 15 mortars was made by combining different types of binders (conforming to UNI EN 459-1 [45]), with two types of river having different grading curves (conforming to UNI-EN 13139 [46]). More precisely, it was used hydraulic lime of natural type NHL 2, NHL 3.5, NHL 5 and Portland Cement Type II/B-LL 32.5 R (PC 32.5). Two mortars are composed of a mixture of NHL 5 and PC 32.5 in order to obtain different classes of compressive strength. The two aggregates are river sand (heterogeneous sand of mainly silica and subordinately calcareous composition of Po river) with a maximum size of 0.2-1.2 mm (type 01) and $0.2-4 \mathrm{~mm}$ (type 04). The grading curves of the aggregates are reported in Fig. 2a, while in the specimen of Fig. 2b, a $4 \mathrm{~mm}$ grain is visible.

The composition of each mortar was obtained with the following proportions by weight: 1 amount of binder and two $(B / A=1 / 2)$ or three $(B / A=1 / 3)$ of aggregate. The quantity of water, in relation to the quantity of binder present $(\mathrm{W} / \mathrm{B})$, varies from mixture to mixture based on the moisture condition of the aggregates. The starting value of $\mathrm{W} / \mathrm{B}$ was 0.5 .

For each mixture, two jet groutings were made; in order to identify each specimen, an alphanumeric acronym was adopted.
The first character is a letter that summarizes the type of used binder and the binder/aggregate ratio, the second character is a number that provides the max aggregate size.

In the second experimental campaign, a set of 9 mortar mixtures was produced. The mortars were made by combining 4 types of binders conforming to UNI EN 459-1 (2015) and river sand with the same characteristics of the first campaign. Specifically, natural type NHL 3.5, slaked lime (SL, classification: CL80-S) and PROMPT Natural Cement $\left(\mathrm{NC}, \mathrm{R}_{\mathrm{C}}=4 \mathrm{MPa}\right.$ after $\left.90 \mathrm{~min}\right)$ were used. The first number of the acronym refers to the maximum aggregate size, the second to the binder type and the last identifies the ratio between binder and aggregate.

Specimens with dimensions of about $160 \times 40 \times 40 \mathrm{~mm}$ were produced and were left to age until a considerable hardening was attained. They were tested after, at least, 9 months from the casting date, when DRMS's force profiles suitable for the occurred maturation were obtained.

Table 1 reports in detail the characteristics of the mortars. The $\mathrm{R}_{\mathrm{C}}$, determined as reported in UNI-EN 1015-11 [47], conditioned on the experimentation year and on the type of binders, are shown in Fig. 3. 


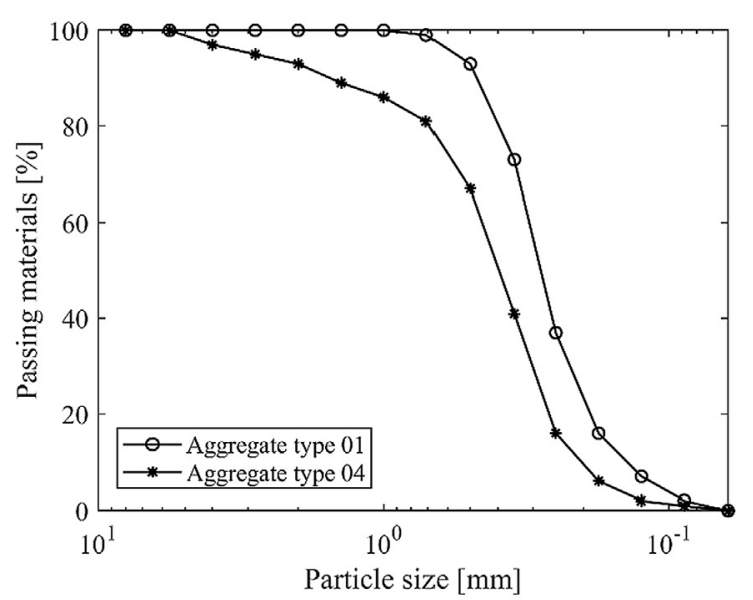

a)

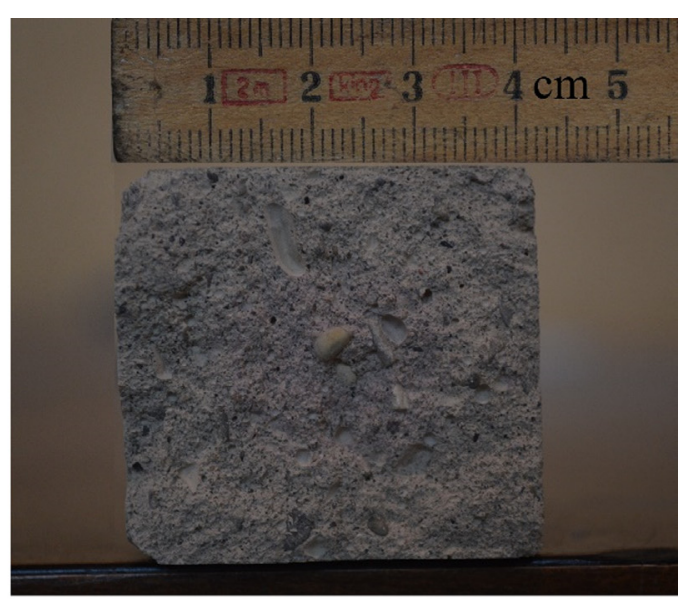

b)

Fig. 2. a) Sand grading curves. b) Mortar showing an aggregate grain with around $4 \mathrm{~mm}$.

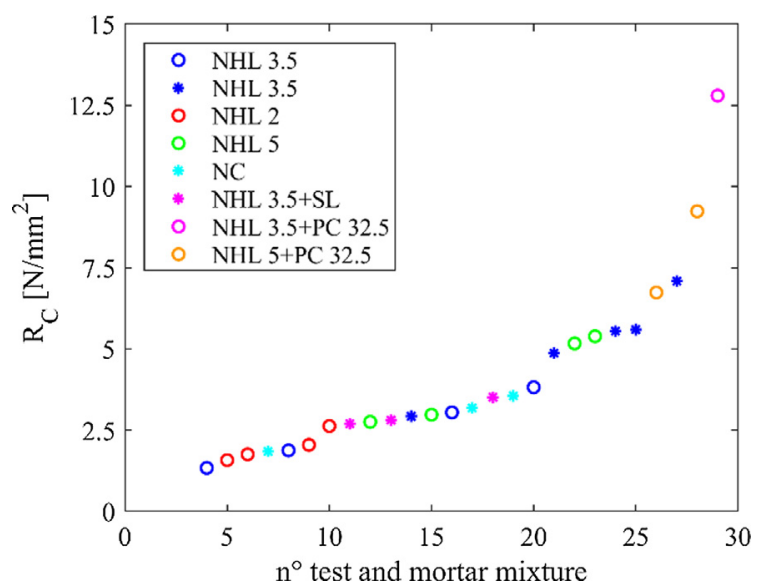

Fig. 3. Compressive strength of the mortars. Categorization by year ( circle $=2008$, star $=2016-18)$ and binder type.

$R_{C}$ is inversely related to $W / B$ and $B / A$ ratios. The highest value of $R_{C}\left(12.80 \mathrm{~N} / \mathrm{mm}^{2}\right)$ is related to $\mathrm{H} 1$ mortar, where the greatest amount of PC 32.5 is present. For the same type and quantity of binder and $B / A$ ratio, the $R_{C}$ generally decreases if larger grain aggregate is present.

\section{Procedure for the treatment of the data}

\subsection{Statistical analysis of the data}

The DRMS measures the force needed for drilling the mortar, DR (N). The profile of DR is heterogeneous and composed of growing and decreasing force stages with the presence of peaks of different intensity. The profile's trend corresponds to the force necessary to crush the components of the mortar until the chips' formation (peaks in Fig. 4a) and then their removal from the holes. Values recorded of DR and their profile obviously depend on several parameters, the most influential are the characteristics of the tested material (composition, aggregate types, etc.), the instrument settings, the drill bits type and their wearing.

Except for the procedure presented in Del Monte and Vignoli [36], the interpretation of the drilling resistance results is usually based on the arithmetic mean $\left(D_{a v}\right)$ or mode $\left(D_{m o}\right)$ of the DR dis- tribution obtained within a chosen depth provided by a defined number of holes.

It has been observed that the profiles of DR on mortars with a large hard grain $(4 \mathrm{~mm})$ have irregular patterns, with high variability and continuous presence of peaks, equal or slightly below the maximum force limit recorded by the instrument. These peaks are due to the work done by the bit in correspondence of aggregates which does not crush but tends to remove them from the hole. Fig. 4 shows the DR profile and histogram distributions of one hole for two mortars with the same composition and setting instrument $(v=40 \mathrm{~mm} / \mathrm{min}$ and $\omega=300 \mathrm{rpm})$ but aggregates of different sizes (1CACN3 and 4CACN3). 1CACN3 has a regular trend without anomalous peaks, a condition that conversely occurs for the mortar with a bigger aggregate. The presence of such peaks does not affect the $\mathrm{DR}_{\mathrm{mo}}$ but influences the $\mathrm{DR}_{\mathrm{av}}$, that is $3.3 \mathrm{~N}$ for $1 \mathrm{CACN} 3(\mathrm{StD}=1.31 \mathrm{~N}$ and $\mathrm{CV}=40 \%$ ), and $7.6 \mathrm{~N}$ for $4 \mathrm{CACN} 3$ ( $\mathrm{StD}=9.2 \mathrm{~N}$ and $\mathrm{CV}=121 \%$ ).

The totality of the data for each mixture was affected by the same problem. Fig. 5a shows the total data distribution for 1 CACN3, Fig. 6 a for 4 CACN3. They are a positive asymmetric data for which $\mathrm{DR}_{\mathrm{av}}$ cannot be considered as a reliable indicator. Thus, statistical treatment was conducted to properly determine the $\mathrm{DR}_{\mathrm{av}}$ of the distribution. To this end, it was calculated the box plot on the total data and the outliers were determined and then excluded to the calculation if they are measures outside the range defined in Eq. (1):

$$
[Q 1-1.5(Q 3-Q 1, Q 3+1.5(Q 3-Q 1)]
$$

where (Q3-Q1) is the interquartile range [36,48].

After the statistical elaborations, the distributions are more symmetric. Fig. 5b represents $1 C A C N 3$ and Fig. 6b 4CACN3. The statistical indexes for the ante and post elaboration data and their variations are reported in Table 2. As expected, 4CACN3 is more affected by the procedure of excluding outliers, with $50 \%$ of variation of the $\mathrm{DR}_{\mathrm{av}}$.

$\mathrm{DR}_{\mathrm{mo}}$ does not change for both types of mortar.

\subsection{Drill bits types and wear}

Before any statistical processing (3.1), acquired data were corrected to consider the variability and the wear of the brill bits due to the perforation in materials [14,35]. The issues are discussed in the following. 


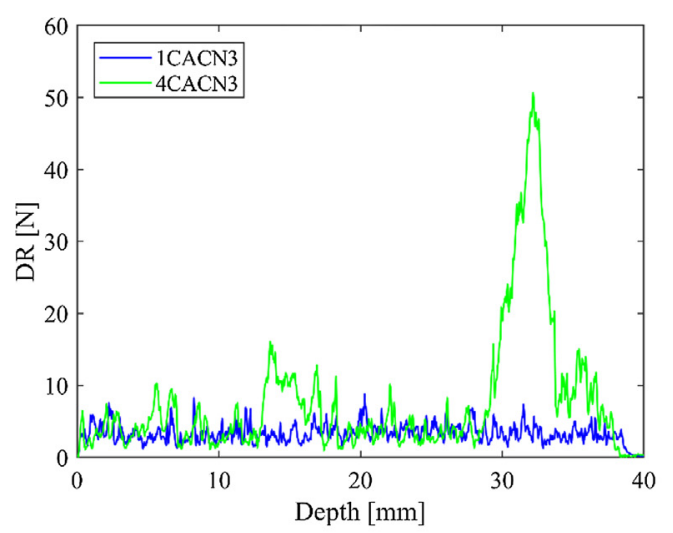

a)

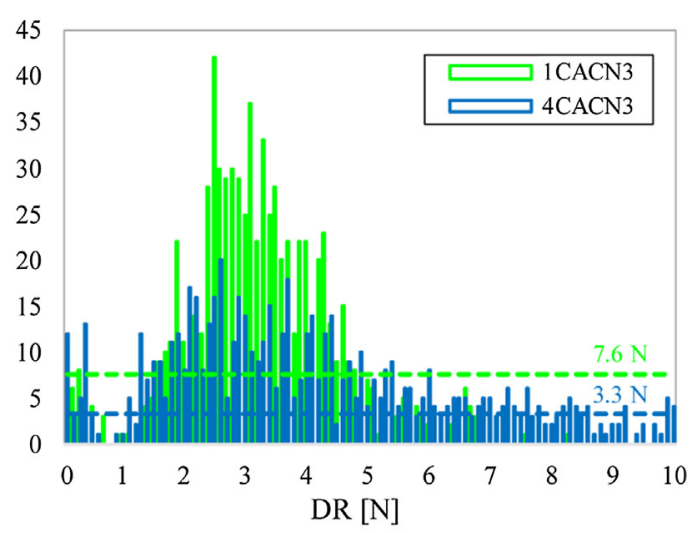

b)

Fig. 4. a) DR trend for $1 C A C N 3$ - 4CACN3 mixtures. b) Histogram distributions of the values recorded for one hole.

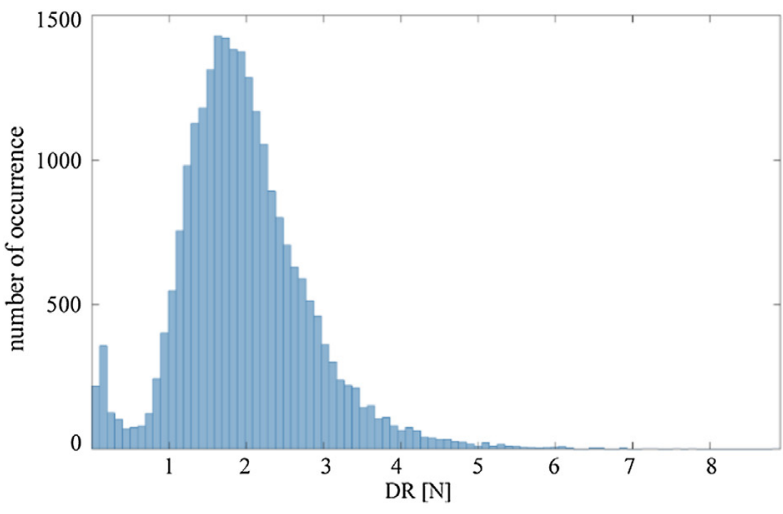

a)

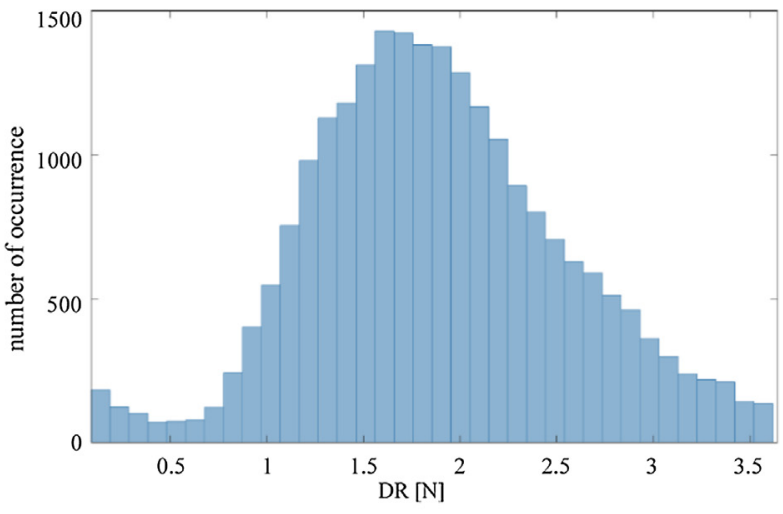

b)

Fig. 5. Data distribution for 30 holes in 1CACN3 mortar; a) before and b) after statistical processing.

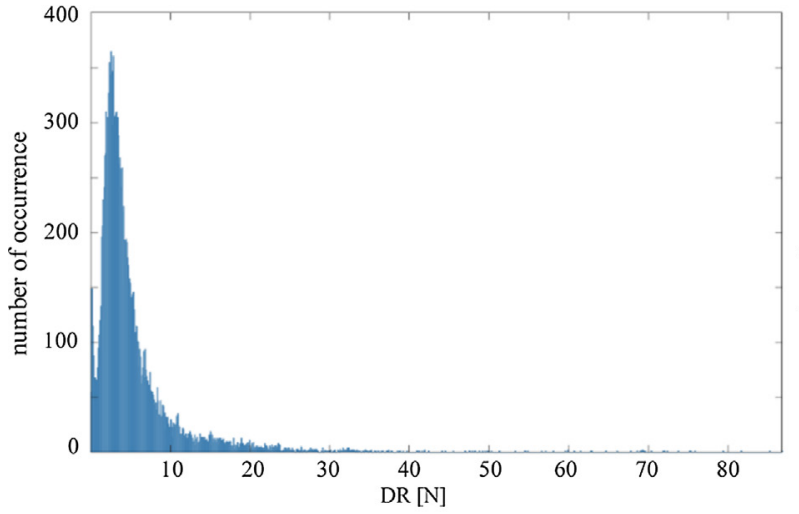

a)

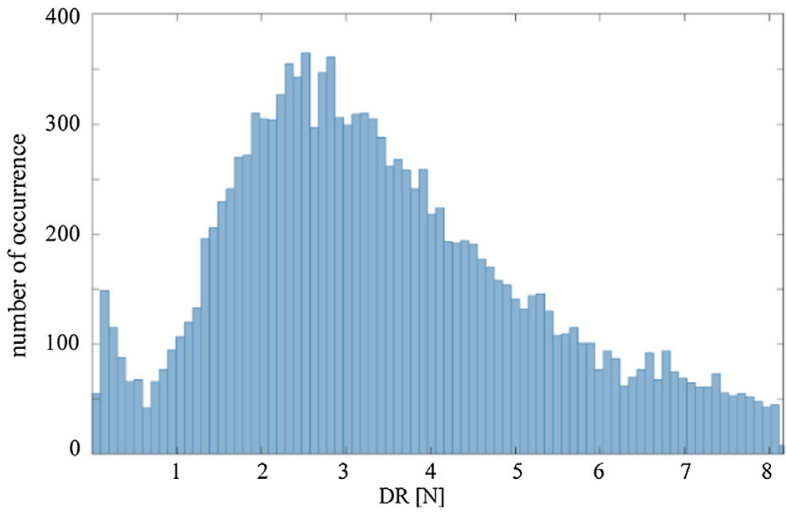

b)

Fig. 6. Data distribution for $4 \mathrm{CACN} 3$ mortar; a) before and b) after statistical processing.

In the experimentations, 5-mm diameter Bosch commercial series B09 were adopted, for their relative low-cost and facility to be found on the market. The use of these commercial drill bits, even if apparently the same type (in terms of brand, size, etc.) generates variability in the results of the DR profile. This has been verified by carrying out the DRMS tests on equal-compressive-strength mortars of the same casting using several drill bits of the same type and measuring different DR values. Table 3 shows the results of
DRMS tests on mortar type 1N3 using Bosch drill bits of the B9 series. Taking as reference the value gained with the B9-02 drill bit (but it would have been possible to take any other) the variation range of the $\mathrm{DR}_{\mathrm{av}}$ were calculated high sensitivity of the results sensitivity of the $\mathrm{DR}_{\mathrm{av}}$.

This phenomenon led to the elaboration of a procedure to eliminate the variability of the results when more than one drill bit is used. Each drill bit must be preventively performed on mortar for 
Table 2

Statistic elaboration results. Mortar 1 CACN3 and 4 CACN3.

\begin{tabular}{|c|c|c|c|c|}
\hline & \multicolumn{2}{|c|}{$1 \mathrm{CACN} 3$} & \multicolumn{2}{|c|}{ 4CACN3 } \\
\hline & $\mathrm{A}$ & $\mathrm{P}$ & $\mathrm{A}$ & $\mathrm{P}$ \\
\hline $\mathrm{DR}_{\mathrm{av}}[\mathrm{N}]$ & 1.94 & 1.88 & 5.17 & 3.42 \\
\hline StD $[N]$ & 0.84 & 0.67 & 5.87 & 1.81 \\
\hline $\mathrm{CV}[\%]$ & 44 & 36 & 114 & 53 \\
\hline SK [-] & 0.80 & 0.15 & 4.88 & 0.53 \\
\hline $\mathrm{DR}_{\mathrm{mo}}[\mathrm{N}]$ & 1.6 & 1.6 & 2.5 & 2.5 \\
\hline $\mathrm{DR}_{\min }[\mathrm{N}]$ & 0.01 & 0.09 & 0.001 & 0.001 \\
\hline Quartile $1[\mathrm{~N}]$ & 1.42 & 1.42 & 2.28 & 2.11 \\
\hline Median Value [N] & 1.85 & 1.83 & 3.53 & 3.14 \\
\hline Quartile $3[\mathrm{~N}]$ & 2.37 & 2.31 & 5.74 & 4.54 \\
\hline $\mathrm{DR}_{\max }[\mathrm{N}]$ & 8.91 & 3.64 & 86.82 & 8.18 \\
\hline
\end{tabular}

$\mathrm{A}=$ Ante elaboration; $\mathrm{P}=$ Post elaboration.

Table 3

Results of DRMS on mortar for comparison specimens (Type $1 \mathrm{~N} 3, R_{C}=2.94 \mathrm{~N} / \mathrm{mm}^{2}$ ).

\begin{tabular}{|c|c|c|c|c|c|}
\hline Progressive & Drill bit ID & $\mathrm{DR}_{\text {hole1 }}[\mathrm{N}]$ & $\mathrm{DR}_{\text {hole2 }}[\mathrm{N}]$ & Average $\mathrm{DR}_{\text {holes1-2 }}[\mathrm{N}]$ & $\Delta[\%]$ \\
\hline 1 & B9-01 & 3.14 & 3.60 & 3.37 & 57 \\
\hline 2 & B9-02 & 2.19 & 2.10 & 2.15 & - \\
\hline 3 & B9-03 & 1.77 & 1.78 & 1.78 & -17 \\
\hline 4 & B9-04 & 2.90 & 3.03 & 2.97 & 38 \\
\hline 5 & B9-05 & 2.21 & 2.49 & 2.35 & 9 \\
\hline
\end{tabular}

comparison, $\mathrm{R}_{\mathrm{C}}=2.94 \pm 0.5 \mathrm{~N} / \mathrm{mm}^{2}$. Then each drill bit should be compared to B9-02, through the $\alpha_{\mathrm{i}}$ coefficient, defined in Eq. (2):

$\alpha_{i}=\left[\frac{D R_{a v, i}}{D R_{a v, B 9-02}}\right]_{m o r t a r=2.90 \mathrm{~N} / \mathrm{mm}^{2}}$

$\overline{D R_{i}}=\frac{D R_{i}}{\alpha_{i}}$

where

$\mathrm{DR}_{\mathrm{av}, \mathrm{i}}$ is the average value of the measures of the first two holes made on the mortar for comparison using the i-drill bit;

$\mathrm{DR}_{\mathrm{av}, \mathrm{B} 9-02}$ is the average value of the measures of the first two holes made using the chosen reference drill bit B9-02 (that is $2.15 \mathrm{~N}$ with reference to Table 3 ).

$\mathrm{DR}_{\mathrm{i}}$ is the generic value of the force measured by the DRMS test using a generic i-drill bit,

$\overline{D R_{i}}$ is the corrected value of the $\mathrm{i}$-drill bit as it would be made of the reference brill bit (B9-02), defined in Eq. (3).

The wear suffered by the drill bit reduces the effectiveness of drill during the cutting, causing the progressive apparent increase in the resistance which is not associated with a real increase of the strength of the materials. Although in relatively low-resistance materials the phenomenon is not extremely influential, the method proposed by Rodrigues and Costa [14] was accounted for. Drill bits were preliminarily tested on specially prefabricated mortars and then their state of function was checked at regular intervals of 10 holes. Each force acquired was subsequently corrected based on the progressive evolution of the force recorded as a function of the total space travelled.

\section{Results}

Considering the statistical approach (3.1), the variability and the wear of the drill bits (3.2), the $\mathrm{DR}_{\mathrm{av}}$ and $\mathrm{DR}_{\mathrm{mo}}$ were determined. Table 4 reports the results $\left(\mathrm{DR}_{\mathrm{av}}, \mathrm{DR}_{\mathrm{mo}}, \mathrm{CV}, \mathrm{StD}, \mathrm{SK}\right)$ for all the mortars in ascending order based on $R_{C}$, both for ante and post elaboration treatment.
The $R_{C}$ are the punctual values of each compression test performed in half specimen which was subsequently subjected to a DRMS test. This is the reason why the values shown in Table 4 are slightly different from those previously reported in Table 1.

The $\mathrm{DR}_{\mathrm{mo}}$ remains almost stable ante and post statistical elaboration, changing only in the $30 \%$ of the cases (Fig. $7 \mathrm{~b}$ ). Conversely, the $\mathrm{DR}_{\mathrm{av}}$ changes significantly: it varies by $40 \%$ (Fig. $7 \mathrm{a}$ ) for mortars with aggregate type 04 . Based on the results here expressed, the mode of untreated data $\left(D_{\mathrm{mo}}\right)$ and the $\mathrm{DR}_{\mathrm{av}}$ post elaboration $\left(D_{\mathrm{av}-\mathrm{P}}\right)$ could be considered reliable indicators of the data distributions of the drilling tests. Predictive models of compression strength will be defined through them in the next section.

CV and SK provide information about the characteristics of the data distribution. The $\mathrm{CV}$ is a non-dimensional dispersion index that shows the variation of the data with respect to the average value, while the SK measures the lack of symmetry of the distribution. SK always takes positive values for the tests, meaning that histograms are asymmetric, with longer tails on the right side (Fig. 4b). The higher the SK the greater the asymmetric distribution: average SK is equal to 3.10 with a peak of 8.17 initially, while after statistical treatment it varies between 0 and 1 with the average value of 0.45 .

CV and SK are positively correlated, as can be seen in the graph in Fig. 8 which depicts their values assumed for the tested mortars. Regression $\mathrm{R}^{2}$ is 0.891 .

Pearson coefficients $\left(\rho_{X Y}\right)$ for each pair of variables were calculated. $\rho_{X Y}$ expresses in the range $[-1,1]$ the measure of the linear correlation between two variables X and Y. 1 is a total positive linear correlation, 0 is no linear correlation, and -1 is a total negative linear correlation. $\rho_{X Y}$ are inserted in the matrix of correlation (Table 5), a symmetric matrix, which immediately provided the existing relations among statistical parameters. The $D_{a v \_} P$ and the $D_{\text {mo }}$ are positively correlated with each other $(\rho=0.988)$, and in both cases with the $R_{C}\left(\rho=0.951\right.$ for $D_{a_{a v}} P$ and $\rho=0.974$ for $D_{R_{m o}}$ ). They are well correlated with the StD_P (Post elaboration), particularly the $\mathrm{DR}_{\mathrm{av} \_} \mathrm{P}(\rho=0.874)$. A negative correlation is quite well defined between $\mathrm{DR}_{\mathrm{av} \_} \mathrm{P}$ and $\mathrm{DR}_{\mathrm{mo}}$ with the CV_P (post elaboration). $R_{C}$ is negatively correlated with CV_P and positively correlated with StD_P, not correlated with SK_A, SK_A or StD_A. 
Table 4

Mortar types: results from DRMS. Ante and post statistical analyses.

\begin{tabular}{|c|c|c|c|c|c|c|c|c|c|c|c|c|c|}
\hline \multirow[t]{2}{*}{ Mortar } & \multirow[t]{2}{*}{$\mathrm{R}_{\mathrm{c}}\left[\mathrm{N} / \mathrm{mm}^{2}\right]$} & \multicolumn{5}{|c|}{ Ante elaboration } & \multicolumn{5}{|c|}{ Post elaboration } & \multirow[t]{2}{*}{$\Delta_{\mathrm{av}}[\%]$} & \multirow[t]{2}{*}{$\Delta_{\mathrm{mo}}[\%]$} \\
\hline & & $\mathrm{DR}_{\mathrm{av}}[\mathrm{N}]$ & $\mathrm{DR}_{\mathrm{mo}}[\mathrm{N}]$ & StD [N] & CV [\%] & SK [-] & $\mathrm{DR}_{\mathrm{av}}[\mathrm{N}]$ & $\mathrm{DR}_{\mathrm{mo}}[\mathrm{N}]$ & StD $[N]$ & CV [\%] & SK [-] & & \\
\hline B4 & 1.34 & 2.34 & 0.50 & 6.36 & 272 & 0.69 & 0.71 & 0.50 & 0.43 & 61 & 7.53 & -70 & 0 \\
\hline $\mathrm{C} 4$ & 1.58 & 2.45 & 0.60 & 5.39 & 220 & 0.78 & 1.13 & 0.60 & 0.78 & 69 & 8.17 & -54 & 0 \\
\hline $\mathrm{C} 1$ & 1.76 & 1.15 & 0.87 & 0.78 & 68 & 0.66 & 0.90 & 0.83 & 0.39 & 43 & 2.09 & -22 & -4 \\
\hline B1 & 1.88 & 1.20 & 0.80 & 0.65 & 54 & 0.60 & 1.09 & 0.80 & 0.49 & 44 & 1.51 & -9 & 0 \\
\hline $\mathrm{F} 4$ & 2.05 & 2.79 & 1.10 & 4.50 & 161 & 0.69 & 1.49 & 1.10 & 0.88 & 59 & 5.86 & -47 & 0 \\
\hline $1 \mathrm{C} 3$ & 2.08 & 1.62 & 1.40 & 0.79 & 49 & 0.29 & 1.51 & 1.40 & 0.51 & 34 & 1.86 & -7 & 0 \\
\hline $\mathrm{F} 1$ & 2.63 & 1.37 & 0.77 & 0.93 & 68 & 0.75 & 1.08 & 0.77 & 0.50 & 46 & 1.98 & -21 & 0 \\
\hline $\mathrm{A} 4$ & 2.76 & 4.06 & 2.05 & 6.10 & 150 & 0.48 & 2.42 & 1.70 & 1.19 & 49 & 6.68 & -41 & -17 \\
\hline 1CACN3 & 2.90 & 1.92 & 1.60 & 0.85 & 44 & 0.15 & 1.94 & 1.60 & 0.62 & 32 & 0.80 & 1 & 0 \\
\hline $\mathrm{A} 1$ & 2.98 & 2.40 & 1.80 & 1.09 & 45 & 0.41 & 2.23 & 1.80 & 0.83 & 37 & 1.36 & -7 & 0 \\
\hline E4 & 3.05 & 3.57 & 1.80 & 5.27 & 147 & 0.46 & 2.10 & 1.70 & 1.05 & 50 & 5.01 & -41 & -6 \\
\hline $1 \mathrm{~N} 3$ & 3.13 & 2.29 & 1.80 & 1.24 & 54 & 0.27 & 2.11 & 1.80 & 0.76 & 36 & 2.49 & -8 & 0 \\
\hline $4 C 3$ & 3.13 & 3.64 & 1.90 & 3.52 & 97 & 0.65 & 2.85 & 1.90 & 1.51 & 53 & 2.84 & -22 & 0 \\
\hline 1CECA3 & 3.56 & 2.38 & 2.20 & 0.95 & 40 & 0.15 & 2.36 & 2.20 & 0.73 & 31 & 0.78 & -1 & 0 \\
\hline $4 \mathrm{CACN} 3$ & 3.57 & 5.07 & 2.50 & 5.77 & 114 & 0.53 & 3.70 & 2.50 & 1.71 & 46 & 4.88 & -27 & 0 \\
\hline E1 & 3.82 & 2.10 & 1.60 & 1.01 & 48 & 0.27 & 1.92 & 1.60 & 0.68 & 35 & 1.64 & -9 & 0 \\
\hline $4 \mathrm{~N} 3$ & 4.73 & 5.97 & 3.30 & 5.42 & 91 & 0.46 & 4.27 & 2.80 & 1.90 & 44 & 3.04 & -28 & -15 \\
\hline D1 & 5.17 & 4.08 & 3.15 & 1.83 & 45 & 0.45 & 3.55 & 3.15 & 1.13 & 32 & 1.33 & -13 & 0 \\
\hline D4 & 5.39 & 7.13 & 3.95 & 7.88 & 110 & 0.46 & 4.62 & 3.45 & 1.95 & 42 & 4.39 & -35 & -13 \\
\hline 1N2 (2016) & 5.60 & 5.64 & 4.90 & 2.89 & 51 & 0.23 & 5.16 & 4.90 & 1.46 & 28 & 3.27 & -9 & 0 \\
\hline 1N2 (2018) & 6.08 & 5.88 & 5.20 & 2.61 & 44 & 0.23 & 5.49 & 4.60 & 1.68 & 31 & 1.43 & -7 & -12 \\
\hline G1 & 6.74 & 4.86 & 4.37 & 1.70 & 35 & 0.37 & 4.54 & 4.17 & 1.13 & 25 & 0.52 & -7 & -5 \\
\hline G4 & 9.24 & 11.72 & 7.27 & 10.11 & 86 & 0.40 & 8.32 & 7.27 & 2.76 & 33 & 3.59 & -29 & 0 \\
\hline $\mathrm{H} 1$ & 12.80 & 9.00 & 8.60 & 2.95 & 33 & 0.27 & 8.37 & 8.20 & 1.73 & 21 & 1.34 & -7 & -5 \\
\hline
\end{tabular}

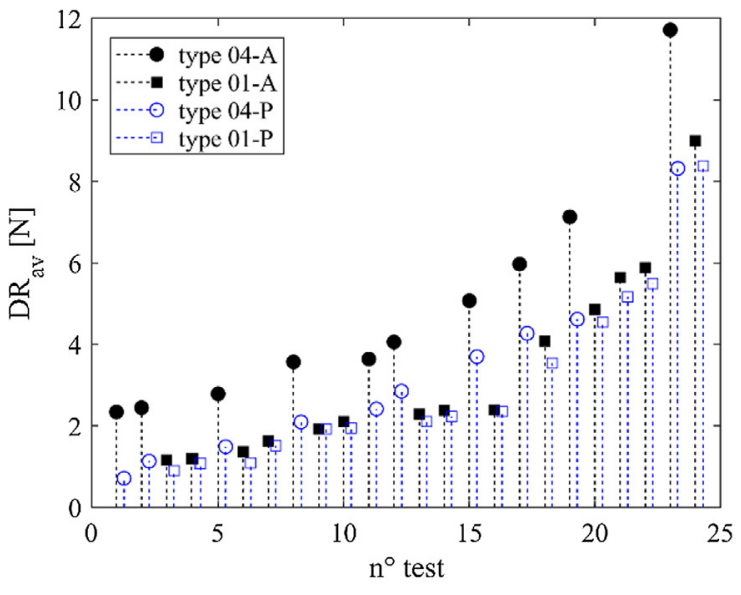

a)

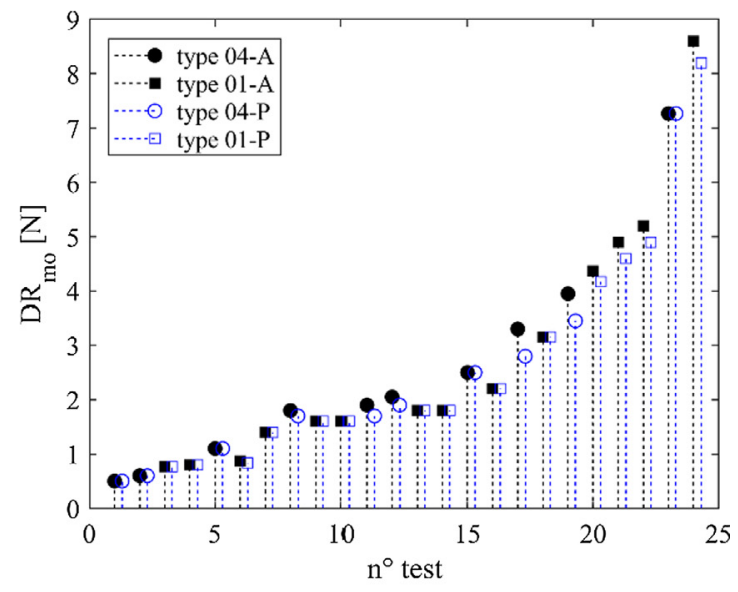

b)

Fig. 7. a) Trend of the $\mathrm{DR}_{\mathrm{av}}$ and $\mathrm{DR}_{\mathrm{mo}}$ ante and post elaboration of the mortar mixtures $(\mathrm{A}=$ ante elaboration, $\mathrm{P}=\mathrm{Post}$ elaboration).

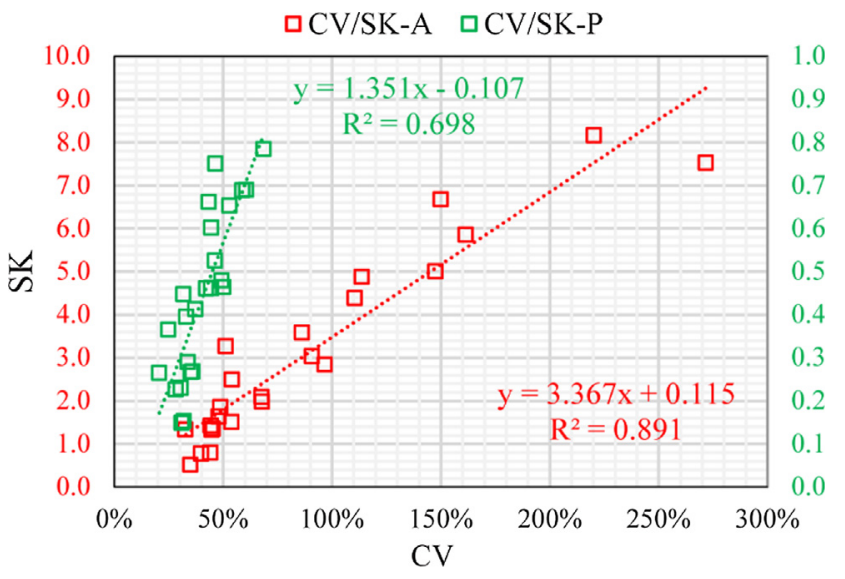

Fig. 8. SK-CV for the mortars, Ante (A) and Post (P) statistical elaborations.

\subsection{Correlations between $D R_{a v}, D R_{m o}$ and $R_{C}$}

Fig. 9 shows the relationship and regressions between $D_{a v \_} P$ and the $\mathrm{R}_{\mathrm{C}}$ for the 24 mortar mixtures (Table 4). Two linear regressions were individuated. The black one (Eq. (4)) is referred to the total data while the red dotted one (Eq. (5)) passes for the origin, following the idea that to a mortar with null compressive strength is associated a null resistance to the penetration. The Eq. (5) provides lower-conservative values of $R_{C}$ than the other for veryweak mortars. The equations are:

$\mathrm{R}_{\mathrm{C}}=1.176 \mathrm{DR}_{\mathrm{av}-\mathrm{P}} \mathrm{P}+0.464$

$\mathrm{R}_{\mathrm{C}}=1.279 \mathrm{DR}_{\mathrm{av}-} \mathrm{P}$

where $R_{C}\left(N / m^{2}\right)$ is the compressive strength estimated by the model, $\mathrm{DR}_{\mathrm{av} \_} \mathrm{P}(\mathrm{N})$ is the average value of the distribution in which extreme outliers were deleted as depicted in paragraph 3 . The cor- 
Table 5

Pearson's coefficients for $\mathrm{DR}_{\mathrm{av}}, \mathrm{DR}_{\mathrm{mo}}, \mathrm{StD}, \mathrm{CV}, \mathrm{SK}$ and $\mathrm{R}_{\mathrm{c}}$. $\mathrm{A}=$ Ante elaboration. $\mathrm{P}=$ Post elaboration.

\begin{tabular}{|c|c|c|c|c|c|c|c|c|c|}
\hline & $\mathrm{DR}_{\mathrm{av} \_} \mathrm{P}[\mathrm{N}]$ & $\mathrm{DR}_{\mathrm{mo} \_} \mathrm{A}[\mathrm{N}]$ & StD_A [N] & StD_P [N] & CV_A [\%] & CV_P [\%] & SK_A [-] & SK_P [-] & $\mathrm{R}_{\mathrm{c}}\left[\mathrm{N} / \mathrm{mm}^{2}\right]$ \\
\hline $\mathrm{DR}_{\mathrm{av}}[\mathrm{N}]$ & 1.000 & 0.988 & 0.404 & 0.874 & -0.335 & -0.588 & -0.214 & -0.404 & 0.951 \\
\hline $\mathrm{DR}_{\mathrm{mo}}[\mathrm{N}]$ & & 1.000 & 0.316 & 0.794 & -0.376 & -0.650 & -0.265 & -0.409 & 0.974 \\
\hline StD_A [N] & & & 1.000 & 0.687 & 0.623 & 0.389 & 0.705 & 0.006 & 0.233 \\
\hline StD_P [N] & & & & 1.000 & -0.080 & -0.246 & 0.066 & -0.339 & 0.714 \\
\hline CV_A [\%] & & & & & 1.000 & 0.874 & -0.214 & -0.404 & -0.408 \\
\hline CV_P [\%] & & & & & & 1.000 & 0.814 & 0.373 & -0.664 \\
\hline SK_A [-] & & & & & & & 1.000 & 0.373 & -0.327 \\
\hline SK_P [-] & & & & & & & & 1.000 & -0.438 \\
\hline $\mathrm{R}_{\mathrm{c}}\left[\mathrm{N} / \mathrm{mm}^{2}\right]$ & & & & & & & & & 1.000 \\
\hline
\end{tabular}

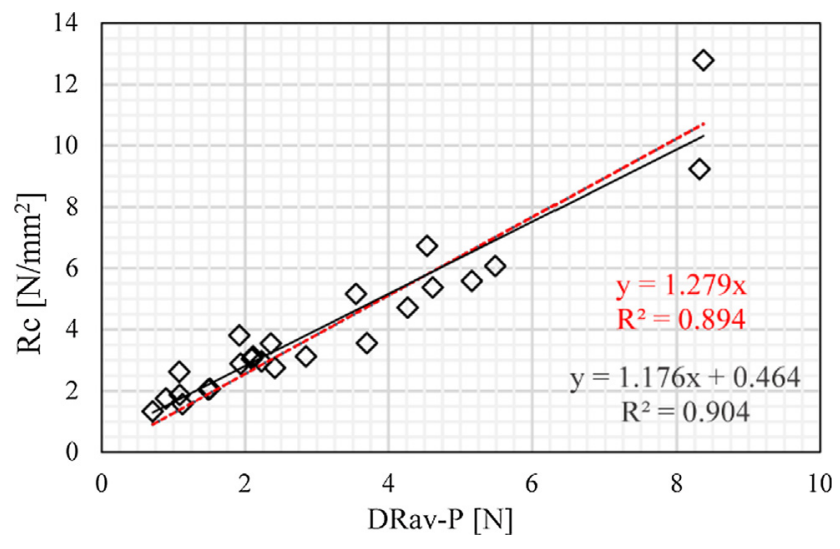

Fig. 9. Relationship between $D R_{a v}$ and $R_{C}$ and proposed correlations.

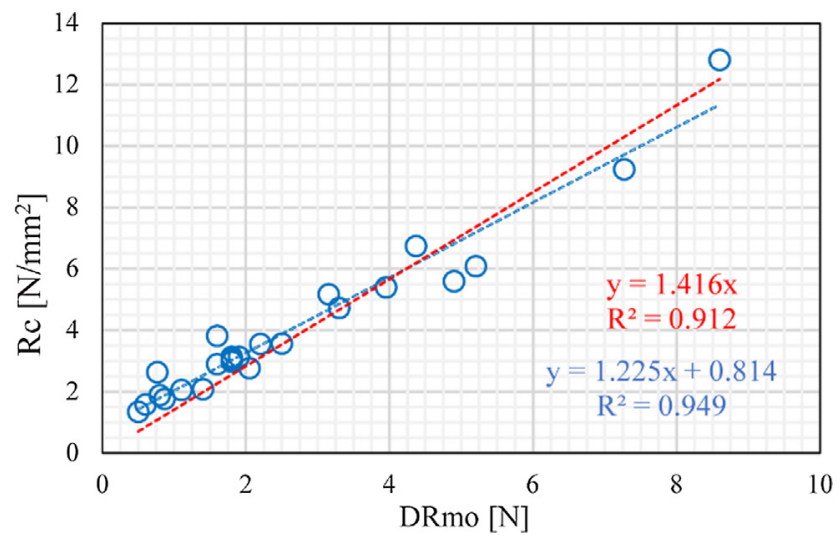

Fig. 10. Relationship between $\mathrm{DR}_{\mathrm{mo}}$ and $\mathrm{R}_{\mathrm{C}}$ and proposed correlations.

relations fit very well the data $\left(R^{2}\right.$ equal to 0.904 and 0.894 , respectively).

As for the $\mathrm{DR}_{\mathrm{av}}$, in Fig. 10 is depicted the relationship between $\mathrm{DR}_{\mathrm{mo}}$ and $\mathrm{R}_{\mathrm{C}}$ and the associated linear regressions of Eqs. (6) and (7):

$\mathrm{R}_{\mathrm{C}}=1.225 \mathrm{DR}_{\mathrm{mo}}+0.814$

$\mathrm{R}_{\mathrm{C}}=1.416 \mathrm{DR}_{\mathrm{mo}}$

where $R_{C}\left(N / \mathrm{mm}^{2}\right)$ is the compressive strength estimated by the model, $\mathrm{DR}_{\mathrm{mo}}(\mathrm{N})$ is the mode of the distribution of the total initial untreated data (ante elaboration). The results of the regression show that the curves validated fit well to data. The coefficient $\mathrm{R}^{2}$ is equal to 0.949 and 0.912 .

Based on the values of Pearson coefficients, multivariate correlations have also been defined, in which the estimated $R_{C}$ is calculated starting from two variables. Several attempts have been made, varying the variables and the type of model. The best correlation was chosen analysing two criteria: i) minimize the error committed between the real $\mathrm{R}_{\mathrm{C}}$ and that predicted and ii) prefer regressions whose errors do not exceed $30 \%$ for the weaker mortars $\left(R_{C}<5 \mathrm{~N} / \mathrm{mm}^{2}\right)$, since they are the ones most frequently found in existing buildings.

The best model was obtained with the $\mathrm{DR}_{\mathrm{av} \_} \mathrm{P}$ and the $\mathrm{CV} \_\mathrm{P}$, for the function described with Eq. (8):

$Z=a \cdot x^{\alpha} \cdot y^{\beta}$

that becomes:

$\mathrm{R}_{\mathrm{C}}=1.230 \cdot \mathrm{DR}_{\mathrm{av}-} \mathrm{P}^{0.647} \cdot \mathrm{CV}_{-} \mathrm{P}^{-0.487}$

where $R_{C}\left(N / m^{2}\right)$ is the compressive strength estimated by the model, $\mathrm{DR}_{\mathrm{av} \_} \mathrm{P}(\mathrm{N})$ and $\mathrm{CV} \_\mathrm{P}[-]$ are the average value and the coefficient of variation of the distribution in which extreme outliers were deleted. Coefficients $a, \alpha$ and $\beta$ were determined through the least squared technique. The graph in Fig. 11a shows the surface representative of Eq. (9) in 3D space ( $D R_{a v \_} P, C V \_P$ and $\left.R_{C}\right)$, while in Fig. $11 \mathrm{~b}$ the blue points represent its projection on the $\mathrm{DR}_{\mathrm{av}}-\mathrm{R}_{\mathrm{C}}$ plane. $R^{2}$ is equal to 0.944 .

In the case of the $\mathrm{DR}_{\mathrm{mo}}$, no multi-regressions can improve the performance of that of Eq. (6).

Errors between the actual $R_{C}$ and those estimated by the models are reported graphically in Fig. 12. The black bars are related to the basic regression using $\mathrm{DR}_{\mathrm{av} \_} \mathrm{P}$ (Eq. (4)). The average error is $1 \%$, the maximum overestimation is $35 \%$ (mortar type 4CACN3, $\mathrm{R}_{\mathrm{C}}=3.57 \mathrm{~N} / \mathrm{mm}^{2}$ ) as well as the minimum (mortar type $\mathrm{F} 1$, $\mathrm{R}_{\mathrm{C}}=2.63 \mathrm{~N} / \mathrm{mm}^{2}$ ). The grey bars refer to the double variable correlation expressed in Eq. (9). With this model, the error is always under the threshold of $30 \%$. The maximum overestimation is $29 \%$ (mortar type $1 \mathrm{C} 3, \mathrm{R}_{\mathrm{C}}=2.08 \mathrm{~N} / \mathrm{mm}^{2}$ ), the minimum is $-28 \%$ and the average is $1 \%$.

The blue bars depict errors committed by the model expressed in Eq. (5). The average error is $1 \%$, the maximum overestimation is $29 \%$ (mortar type 1C3), the minimum is $-33 \%$.

Based on the analysis of the exposed criteria, it is reasonable to identify the regressions with the $\mathrm{DR}_{\mathrm{mo}}$ (Eq. (5)) and multivariate regression of Eq. (9) as the most reliable.

The $R_{C}$ covered by the samples are in the range $1.34-12.80 \mathrm{~N} /$ $\mathrm{mm}^{2}$. 6 of them are less than $2.5 \mathrm{~N} / \mathrm{mm}^{2}$, while most mortars (11samples) have $R_{C}$ in the range $2.5-5.0 \mathrm{~N} / \mathrm{mm}^{2}$. Therefore, the correlations proposed have reliability in this range of values. Despite the high $R^{2}$ of the model, for $R_{C}>7.5 \mathrm{~N} / \mathrm{mm}^{2}$ or $\mathrm{R}_{\mathrm{C}}<1.5 \mathrm{~N} / \mathrm{mm}^{2}$ for which only 3 samples are present, it is advisable to use the correlation with caution. The Eq. (9) can be used when the CV_P is in the range $25-65 \%$, as for the analysed case studies.

An attempt was made to identify different correlations for subsets of specimens as a function of mortar strength, considering only the specimens characterized by $R_{C}<5 \mathrm{~N} / \mathrm{mm}^{2}$. 17 tests are 

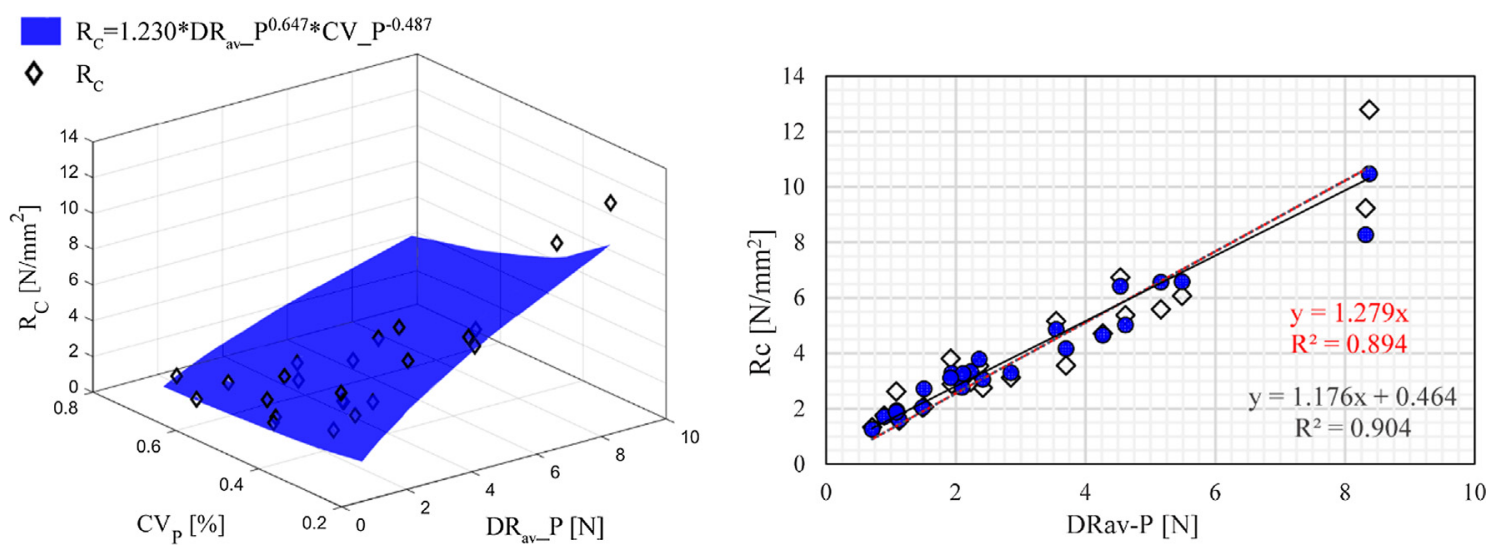

Fig. 11. Relationship between $D R_{a v}-C V \_P-R_{C}$ and proposed correlations. a) $3 D$ space $D R_{a v}-C V \_P-R_{C}$; $\left.b\right) D R_{a v}-R_{C} p l a n$.

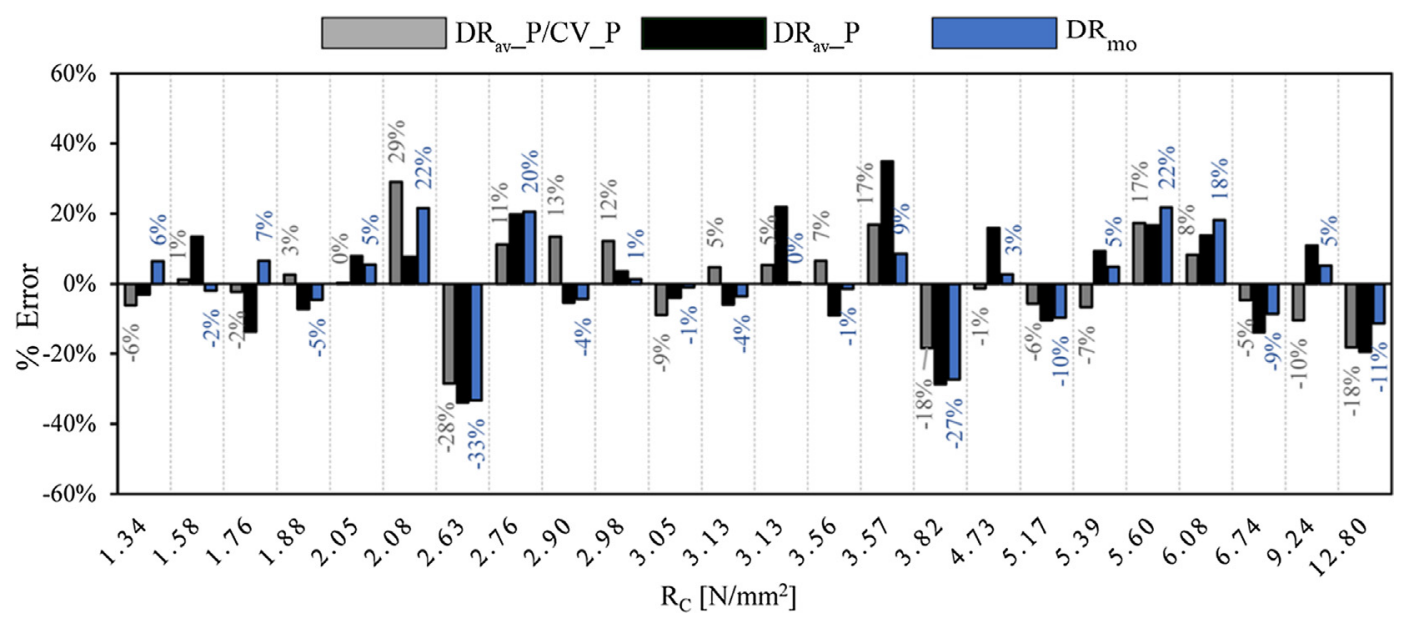

Fig. 12. Errors between real and predicted compressive strengths using correlations with $D_{a v}$ and $D R_{m o}$.

available. Less effective correlations were always obtained in which $\mathrm{R}^{2}$ decreases, but errors between predictive and real resistances remain at least stable. $\mathrm{R}^{2}$ drops to 0.754 for standard correlation using $\mathrm{DR}_{\mathrm{av} \_} \mathrm{P}, 0.814$ using $\mathrm{DR}_{\mathrm{mo}}$.

The correlation considering both $\mathrm{DR}_{\mathrm{av} \_} \mathrm{P}$ and $\mathrm{CV} \_\mathrm{P}$ changes in Eq. (10):

$\mathrm{R}_{\mathrm{C}}=1.379 \cdot \mathrm{DR}_{\mathrm{av}}{ }^{0.566} \cdot \mathrm{CV} \mathrm{P}^{-0.487}$

\subsection{Definition of the stepwise process to individuate compression strength in mortar joints}

A standard procedure has been established in order to easy make use of the proposed correlations in the case of mortar joints. The stepwise process concerns:

1. determination of the tested masonry area. If the masonry is exposed, clean the surface of the masonry and identify the mortar joints to be tested. If the masonry has plaster, the operations are preceded by the removal of at least $1 \mathrm{~m} \times 1 \mathrm{~m}$ of plaster in order to discover the masonry types. The joints must be far from openings and cleaned.

2. drill bits. Choose drill bits among those existing on the market;

3. setting parameters. Set parameter of DRMS Cordless to: $v=40 \mathrm{~mm} / \mathrm{min}$ and $\omega=300 \mathrm{rpm}$;

4. test and calibration of the drill bits. For each drill bit, drill 2 holes on a mortar sample with a maximum aggregate size of $1 \mathrm{~mm}$ and compressive strength approximately equal to $2.94 \mathrm{~N} \pm 0.5 \mathrm{~N}$. Calculate the average value of the DR of the 2 holes $\left(\mathrm{DR}_{\mathrm{av}, \mathrm{i}}\right)$. Align the behaviour of the used drill bit to the B9-02, calculating the normalization coefficients $\alpha_{i}$ as the ratio of $\mathrm{DR}_{\mathrm{av}, \mathrm{i}}$ and $\mathrm{DR}_{\mathrm{av}, \mathrm{B9}-02}$ (Table 3);

5. test performing. Make at least 20 holes $40 \mathrm{~mm}$-depth on mortar joints for each zone to be investigated;

6. wear of the drill bit. Evaluate and account the wearing of the drill bit (paragraph 3.3);

7. results. Define the results of the experiments tests:

a. apply the $\alpha_{\mathrm{i}}$ and wear coefficient rate to all extracted data by the software of Sint technology;

b. define the $x_{1}-x_{2}$ range, (ie [5-35] $\mathrm{mm}$ );

c. evaluate the $\mathrm{DR}_{\mathrm{mo}}$ for distribution of the total data;

d. apply the statistical procedure (outliers deleting) and define the $\mathrm{DR}_{\mathrm{av} \_} \mathrm{P}$ and $\mathrm{CV} \_\mathrm{P}$;

8. mortar's compression strength. Apply the proposed correlations replacing the values of $D_{a v} R_{a}, C V_{-} P$ and $D_{m o}$ in equations defined in paragraph 4.1 and determine predicted $R_{C}$ of the mortars.

Examples of applications of the procedure are given in the next paragraph.

\section{Application of the proposed methodology to some cases study}

The stepwise process was applied on different walls of three existing masonry buildings of Tuscany. A brief description of the 


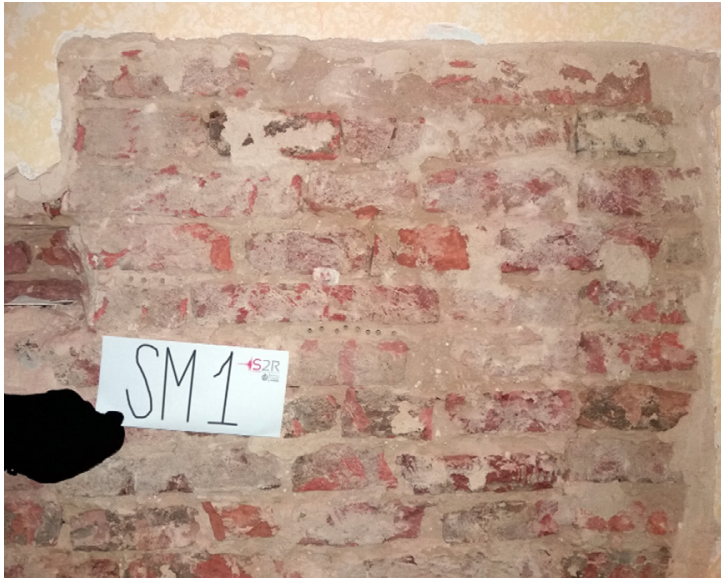

Fig. 13. Case study n.1. Window of masonry after plaster removal.

structures and panels, together with the results, are stated in the following.

\subsection{Case study 1 (CS1)}

The first case study refers to a private historical masonry structure characterized by three floors located in the province of Arezzo. The building dates to the end of the 19th century and it is composed of stone and brick masonry panels. By visual inspections and considering the historic period of construction, both masonry types are hypothesized to be made of limed based mortar. Solid brick masonry (Fig. 13) was tested.

\subsection{Case study 2 (CS2)}

The second case study is a modern two floors masonry building in hollow brick elements $(26 \times 25 \times 12 \mathrm{~cm})$ - with $55-67 \%$ of voids - located near Pistoia. The mortar is dark grey, apparently constituted by a cementitious binder. The masonry is composed of one layer with staggered vertical bed joints and perfectly horizontal aligned (Fig. 14a,b).

\subsection{Case study 3 (CS3)}

The third case study is a historical masonry aggregate in Firenze, composed of different structural units. The vertical load-bearing structure is mainly made of stone and brick masonry, with an original structure dating back to the 14th century. The stone masonry tested, in which a strong inclusion of solid bricks is returned, is depicted in Fig. 15.

\subsection{Results}

The tests were done after removing the plaster. Parameters were set in order to account for the results of laboratory experimentation $(v=40 \mathrm{~mm} / \mathrm{min}$ and $\omega=300 \mathrm{rpm})$. Bosch commercial series B09 drill bits were adopted. The holes were made along the horizontal mortar joints (ie. Fig. 14c) and the $\mathrm{x}_{1}-\mathrm{x}_{2}$ range was [5-35] mm.

Fig. 16 shows the acquisition of one hole for the CS1 and CS2. The first force appears more homogeneous, due to the limebased mortar and the supposed fine aggregate, while the second has as a more irregular path, numerous peaks but higher resistance to the perforation. The outlier limits to be excluded in the calculation are in the ratio $1 / 3$.

The compression strengths predicted by the model are shown in Table 6. Highlighted in bold there are the strengths provided by the two more reliable correlations: using $\mathrm{DR}_{\mathrm{mo}}$ (Eq. (6)) and $\mathrm{DR}_{\mathrm{av}-\mathrm{P}}$ CV_P (Eq. (9)). The results agree with a maximum difference of $12 \%$ for the CS2.

For CS1, considering only the $\mathrm{DR}_{\mathrm{av}-} \mathrm{P}$ correlations, the greatest resistance is provided by the multivariate correlation, since the

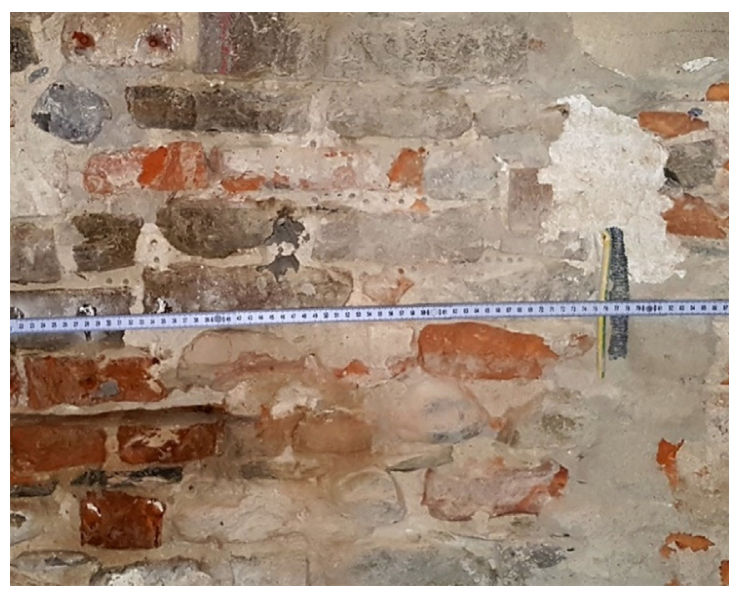

Fig. 15. Case study n.3. Window of masonry after plaster removal.

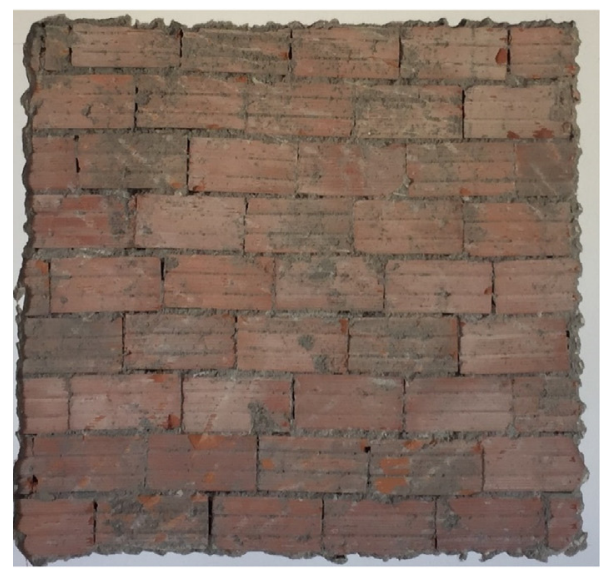

a)

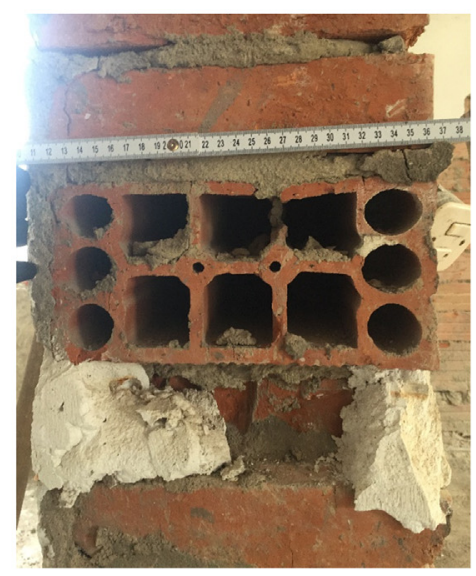

b)

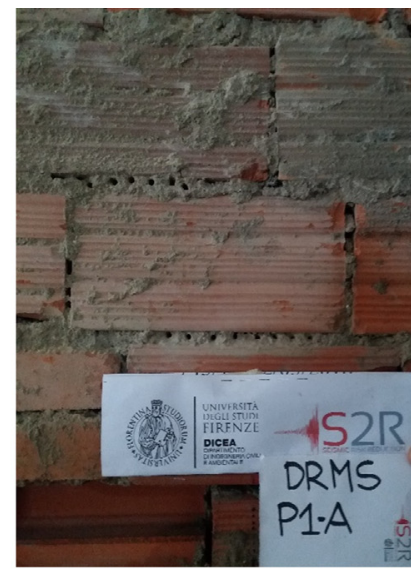

c)

Fig. 14. Case study n.2. a) Window of masonry after plaster removal; b) cross section, composed by one single layer; c) in situ DRMS test. 


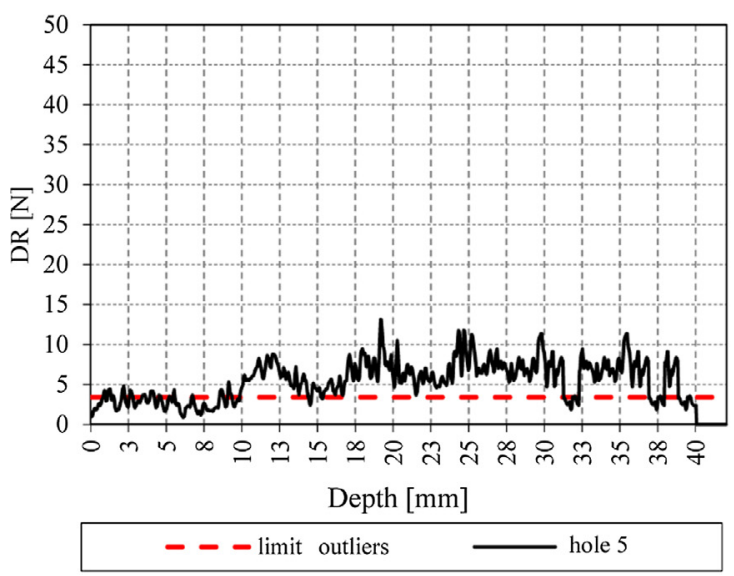

a)

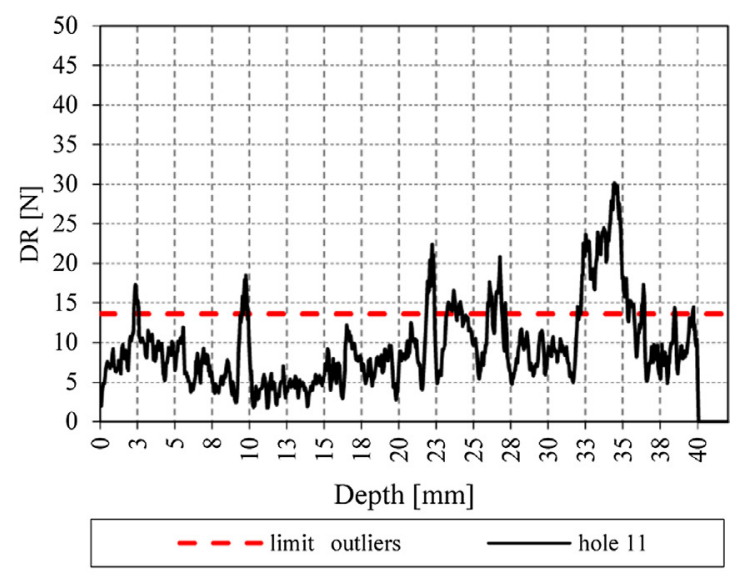

b)

Fig. 16. Example of DR trend for one hole of CS1 (a) and CS2 (b), with the individuation of the outlier limits.

Table 6

Results for in situ applications (5-35 $\mathrm{mm}$ of investigation depth range).

\begin{tabular}{|c|c|c|c|c|c|c|}
\hline \multirow[t]{2}{*}{ CS } & \multirow{2}{*}{$\begin{array}{l}\text { Ante elaboration } \\
\mathrm{DR}_{\mathrm{mo}}[\mathrm{N}]\end{array}$} & \multicolumn{2}{|c|}{ Post elaboration } & \multirow[t]{2}{*}{$\mathrm{R}_{\mathrm{c}}\left(\mathrm{DR}_{\mathrm{av}}\right) \mathrm{Eq} \cdot(4)\left[\mathrm{N} / \mathrm{mm}^{2}\right]$} & \multirow[t]{2}{*}{$\mathrm{R}_{\mathrm{c}}\left(\mathrm{DR}_{\mathrm{av}}-\mathrm{CV}\right)$ Eq. (9)[N/mm $\left.{ }^{2}\right]$} & \multirow[t]{2}{*}{$\mathrm{R}_{\mathrm{c}}\left(\mathrm{DR}_{\mathrm{mo}}\right)$ Eq. $(6)\left[\mathrm{N} / \mathrm{mm}^{2}\right]$} \\
\hline & & $\mathrm{DR}_{\mathrm{av}}[\mathrm{N}]$ & CV [\%] & & & \\
\hline 1 & 2.50 & 2.27 & 29 & 3.13 & 3.82 & 3.88 \\
\hline 2 & 4.70 & 6.06 & 46 & 7.59 & 5.76 & 6.57 \\
\hline 3 & 1.90 & 2.34 & 54 & 3.22 & 2.88 & 3.14 \\
\hline
\end{tabular}

model exploits the low value of CV_P (29\%), denoting low dispersion of the data. The result, even not conservative, agrees with the result predicted by the correlation with $\mathrm{DR}_{\mathrm{mo}}$.

In the case of the mortar with higher characteristics (CS2), the predicted $R_{C}$ varies by more than $25 \%$, due to the evident difference between $\mathrm{DR}_{\mathrm{mo}}$ and $\mathrm{DR}_{\mathrm{av}} \mathrm{P}$ values. The correlation only considering $D_{\mathrm{av}} \mathrm{P}$ overestimates the $\mathrm{R}_{\mathrm{c}}$. The multivariate regression, since it considers the high value of $C V$, lower the $R_{C}$ to be minor of the one estimated using $\mathrm{DR}_{\mathrm{mo}}$.

CS3 refers to medium compressive strength. Since also in the case of post elaboration $\mathrm{CV}$ is high ( $>50 \%$ ), denoting high variability of the results, the more plausible result could be that of the model $\mathrm{DR}_{\mathrm{av} \_} \mathrm{P}-\mathrm{CV} \_\mathrm{P}$.

However, the correlation with $\mathrm{DR}_{\mathrm{mo}}$ is the fastest to make and, even if it does not consider the CV, provided good results and it surely can be used for preliminary estimation of the strength.

About the values of the mechanical characteristics defined by the Italian Code (MIT 2019) that can be adopted in the structural analyses, for both the historical masonry types, there the extremes to consider a good quality of the mortar. This means that the basic mechanical characteristics of the stone masonry type of CS3 (Table C8.5.I of MIT 2019) can be multiplied for 1.4 (Table C8.5.II of MIT 2019) and those of brick masonry of CS1 for $\mathrm{f}_{\mathrm{m}}^{0.35}=1.49$, in which $\mathrm{f}_{\mathrm{m}}$ is the mortar compression strength $\left(\mathrm{N} / \mathrm{mm}^{2}\right)$, found with the model.

For the modern masonry type of CS2, the mortar is good having an $R_{C}$ higher than $5 \mathrm{~N} / \mathrm{mm}^{2}$ considering the results of all the predictive models.

\section{Conclusions}

In this paper, the drilling resistance technique is presented as a Minor Destructive Test to estimate the compressive strength of mortars.

A set of mortar mixtures with compressive strengths in the range $1.34-12.80 \mathrm{~N} / \mathrm{mm}^{2}$ have been produced in laboratory exper- imental campaigns in the year 2008 and in the period 2016-2018 in the Structures and Materials Testing Laboratory at the University of Florence, to reproduce characteristics of typical mortars of historic buildings, commonly encountered in Tuscany (Italy). The mixtures were subjected both to DRMS and compressive laboratory tests.

Considering the results of the drilling measurement distributions, both the $\mathrm{DR}_{\mathrm{mo}}$ and the $\mathrm{DR}_{\mathrm{av}}$ (the latter obtained by a statistical treatment in which extreme outliers were deleted) have been taken as reference values for each test. According to the results of scientific literature, the values of the SK and the CV of the recorded data give substantial information about the heterogeneity and the quality of the mortar types.

The most noteworthy results are the definition of stable correlations between the compressive strength, $R_{C}$, and the parameters of the DRMS results $\left(D_{\mathrm{av}}, \mathrm{DR}_{\mathrm{mo}}\right.$ and $\left.\mathrm{CV}\right)$ and a stepwise process to be followed to determinate the in situ compressive strength of mortar joints.

The most reliable correlations to estimate the $R_{C}$, for setting parameter of $v=40 \mathrm{~mm} / \mathrm{min}$ and $\omega=300 \mathrm{rpm}$, are:

- using $\mathrm{DR}_{\mathrm{mo}} . \mathrm{R}_{\mathrm{C}}=1.225 \mathrm{DR}_{\mathrm{mo}}+0.814$ that shows an average error of around $0.38 \mathrm{~N} / \mathrm{mm}^{2}$ of overestimation;

- using $\mathrm{DR}_{\mathrm{av} \_} \mathrm{P}$ and CV_P $(\mathrm{P}=$ post elaboration $)$. $\mathrm{R}_{\mathrm{C}}=1.230 \cdot \mathrm{DR}_{\mathrm{av}} \mathrm{P}^{0.647} \cdot \mathrm{CV}_{-} \mathrm{P}^{-0.487}$ that shows an average error of $0.33 \mathrm{~N} / \mathrm{mm}^{2}$ of overestimation, a maximum punctual overestimation of $29 \%$.

The stepwise procedure, well defined through eight steps, can be considered a guideline to follow to being addressed in the choice of the parameters of the DRMS and in the evaluation and interpretation of the test results.

It remains to work in the field of mortars outside the range foreseen by the correlations, especially in the case of very lowcompressive mortars, typical of masonry types of the rural and historical city centers, that the Italian building Code identifies with $\mathrm{R}_{\mathrm{C}}<1.5 \mathrm{~N} / \mathrm{mm}^{2}$. 


\section{Acknowledgments}

This project was supported by the ReLUIS 2014-16 research program on masonry buildings. Authors thank the Structures and Materials Testing Laboratory team of the Department of Civil and Environmental Engineering in Florence, Eng. Antonio Pittelli and Spin-Off S2R team for their support during all the phases of the experimental campaign.

\section{Appendix A. Supplementary data}

Supplementary data to this article can be found online at https://doi.org/10.1016/j.conbuildmat.2019.117563.

\section{References}

[1] S. Boschi, C. Bernardini, A. Borghini, A. Ciavattone, E. Del Monte, S. Giordano, A. Vignoli, N. Signorini, Mechanical characterization of particular masonry panels in Tuscany. Proceedings of the 16th International Brick and Block Masonry Conference, IBMAC 2016, Pages 1447-1456. Padova; Italy; 26-30 June 2016.

[2] G. Fiorentino, A. Forte, E. Pagano, et al., Damage patterns in the town of Amatrice after August 24th 2016 Central Italy earthquakes, Bull. Earthq. Eng. 16 (2018) 1399, https://doi.org/10.1007/s10518-017-0254-z.

[3] R. Sisti, M. Di Ludovico, A. Borri, A. Prota, Damage assessment and the effectiveness of prevention: the response of ordinary unreinforced masonry buildings in Norcia during the Central Italy 2016-2017 seismic sequence, Bull. Earthq. Eng. (2018), https://doi.org/10.1007/s10518-018-0448-z.

[4] M. Betti, A. Borghini, S. Boschi, A. Ciavattone, A. Vignoli, Comparative seismic risk assessment of basilica-type churches, J. Earthquake Eng. 22 (sup1) (2018) 62-95, https://doi.org/10.1080/13632469.2017.1309602.

[5] G. Castori, A. Borri, A. De Maria, M. Corradi, R. Sisti, Seismic vulnerability assessment of a monumental masonry building, Eng. Struct. 136 (2017) 454465, https://doi.org/10.1016/j.engstruct.2017.01.035.

[6] G. Bartoli, M. Betti, S. Monchetti, Seismic risk assessment of historic masonry towers: comparison of four case studies, J. Perform. Constr. Facil. 31 (5) (2017) 04017039, https://doi.org/10.1061/\%28ASCE\%29CF.1943-5509.0001039.

[7] S. Boschi, A. Borghini, B. Pintucchi, N. Zani, Seismic vulnerability of historic masonry buildings: a case study in the center of Lucca, Procedia Struct. Integrity 11 (2018) (2018) 169-176.

[8] C. Bernardini, R. Maio, S. Boschi, T.M. Ferreira, R. Vicente, A. Vignoli, The seismic performance-based assessment of a masonry building enclosed in aggregate in Faro (Portugal) by means of a new target structural unit approach,

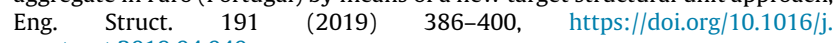
engstruct.2019.04.040.

[9] S. Boschi, L. Galano, A. Vignoli, Mechanical characterisation of tuscany masonry typologies by in situ tests, Bull. Earthquake Eng. 17 (2019) 413, https://doi.org/ 10.1007/s10518-018-0451-4.

[10] NTC 2008 (2008) Ministerial Decree of 14 January 2008. New Technical Standards for Constructions, published in the Official Journal of the Italian Republic n.29 of 04 February 2008. (in Italian).

[11] NTC 2018 (2018) Ministerial Decree of 17 January 2008. Update of "New Technical Standards for Constructions", published in the Official Journal of the Italian Republic n.42 del 20 February 2018 (in Italian).

[12] EN 1996-1-1 (2005) Eurocode 6: Design of masonry structures - Part 1-1: General rules for reinforced and unreinforced masonry structures.

[13] UNI EN 772-1 (2002) Methods of test for masonry units. Determination of compressive strength.

[14] J. Delgado Rodrigues, D. Costa, A new interpretation methodology for microdrilling data from soft mortars, J. Cultural Heritage 22 (December 2017) (2016) 951-955, https://doi.org/10.1016/j.culher.2016.06.010.

[15] MIT 2009 (2009) Instructions for the application of «New Technical Standards for Construction" as stated in the Ministerial Decree of 14 January 2008, published in the Official Journal of the Italian Republic, No 47 of 26 February 2009 (in Italian).

[16] MIT 2019 (2019) Instructions for the application of «Update of "New Technical Standards for Construction"» as stated in the Ministerial Decree of 17 January 2018, published in the Official Journal of the Italian Republic, No 7 of 21 January 2019 (in Italian).

[17] A. Vignoli, S. Boschi, C. Modena, E. Cescatti, In-situ mechanical characterization of existing masonry typologies: a research project in Italy finalized to update the structural codes. In: Proceedings of XVI international brick and block masonry conference 27-29 June 2016, Padova, Italy, pp. 1983-1991. ISBN: 978-1-138-02999-6.

[18] S. Yang, R. Gu, S. Cao, New local compression test to estimate in situ compressive strength of masonry mortar, J. Test. Eval. 44 (1) (2016) 67-76, https://doi.org/10.1520/JTE20130088. ISSN 0090-3973.

[19] L. Pelà, P. Roca, A. Aprile, Combined in-situ and laboratory minor destructive testing of historical mortars, Int. J. Archit. Heritage 12 (3) (2018) 334-349, https://doi.org/10.1080/15583058.2017.1323247.
[20] D. Łątka, P. Matysek, Assessment of the compressive strength of lime mortar in the joints of brick walls - case study. MATEC Web of Conferences 163, 02006 (2018). doi: 10.1051/matecconf/201816302006.

[21] R. Felicetti, N. Gattesco, A penetration test to study the mechanical response of mortar in ancient masonry buildings, Mater. Struct. 31 (1998) (1998) 350-356, https://doi.org/10.1007/BF02480678.

[22] D. Liberatore, N. Masini, L. Sorrentino, V. Racina, M. Sileo, O. AlShawa, L. Frezza, Static penetration test for historical masonry mortar, Constr. Build. Mater. 122 (2016) 810-822, https://doi.org/10.1016/j.conbuildmat.2016.07.097.

[23] N. Gucci, R. Barsotti, A non-destructive technique for the determination of mortar load capacity in situ, Mater. Struct. 28 (1995) 276-283.

[24] ASTM C805/C805M-13a, Standard Test Method for Rebound Number of Hardened Concrete, ASTM International, West Conshohocken, PA, 2013, www.astm.org, 2013.

[25] EN 12504-2, Testing concrete in structures - Part 2: Non-destructive testing. Determination of rebound number, 2012.

[26] RILEM TC 127-MS.D.2, Determination of masonry rebound hardness, Materials and Structures, Volume 34, 1998.

[27] L.J.A.R. Van Der Klugt, The pointing hardness tester - an instrument to meet a need, Mater. Struct. 24 (1991) (1991) 471-476.

[28] R. Schmiedmayer, Nondestructive in situ determination of mortar load capacity using a modified Schmidt rebound hammer, in: Proceedings of XI International Brick and Block Masonry Conference 14-16 ottobre 1997 Shangai, China, pp. 367-375, 1997. ISBN: 978-1-138-02999-6.

[29] P.D.V. Christiansen, In situ determination of the compressive strength of mortar joints using an X-drill, Mason. Int. 24 (2011) (2011) 31-38.

[30] D. Marastoni, A. Benedetti, L. Pelà, Evaluation of mortar strength in existing masonry structures through a Minor Destructive Technique, in: Proceedings of XVI International Brick and Block Masonry Conference 27-29 june 2016, Padova, Italia, pp. 1699-1706, 2016. ISBN: 978-1-138-02999-6.

[31] D. Marastoni, A. Benedetti, L. Pelà, G. Pignagnoli, Torque Penetrometric Test for the in-situ characterisation of historical mortars: fracture mechanics interpretation and experimental validation, Constr. Build. Mater. 157 (2017) (2017) 509-520, https://doi.org/10.1016/j.conbuildmat.2017.09.120.

[32] P. Tiano, J. Delgado Rodrigues, E. De Witte, V. Verge-Belmin, S. Massey, R. Snethelage, D. Costa, L. Cadot-Leroux, E. Garrod, B. Singer, The conservation of monuments: a new method to evaluate consolidating treatments, Int. J. Restauration Build. Monuments 6 (2) (2000) 133-150.

[33] M. Theodoridou, F. Dagrain, I. Ioannou, Micro-destructive cutting techniques for the characterization of natural limestone, Int. J. Rock Mech. Min. Sci. 76 (2015) 98-103, https://doi.org/10.1016/j.ijrmms.2015.02.012.

[34] F. Chagneau, M. Levasseur, Contrôle des matériaux de construction par dynamostratigraphie, Mater. Struct. 22 (1989) 231-236.

[35] M. Pamplona, M. Kocher, R. Snethlage, L.A. Barros, Drilling resistance: overview and outlook, Zeitschrift der Deutschen Gesellschaft für

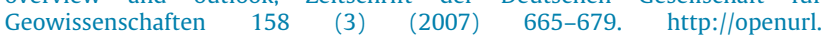
ingenta.com/content/xref?genre=article\&issn=1860-

$1804 \&$ volume $=158 \&$ issue $=3 \&$ spage $=665$.

[36] E. Del Monte, A. Vignoli, In situ mechanical characterization of the mortar in masonry buildings with DRMS. In: 1st international RILEM symposium on site assessment of concrete, masonry and timber structures, Varenna, Italy, 1-2 September 2008, pp 421-430.

[37] M. Lawrence, P. Walker, The measurement of the carbonation profile in lime mortars using a drilling resistance measurement system, in: 11th International Congress on Deterioration and Conservation of Stone, Toruń, $1-8,2008$.

[38] D. Costa, A. Magalhães, M. do Rosário Veiga, Characterisation of mortars using DRMS: tests on field panels samples, in: 2nd Historic Mortars Conference HMC2010, Prague, 2010. http://link.springer.com/10.1007/978-94-007-46350 .

[39] R. Nogueira, A.P. Ferreira Pinto, A. Gomes, Contribution of the Drilling Resistance Measurement System to the Characterisation of Ancient Mortars, in: 3rd Historic Mortars Conference, Glasgow, 2013.

[40] R. Nogueira, A.P. Ferreira Pinto, A. Gomes, Assessing mechanical behavior and heterogeneity of low-strength mortars by the drilling resistance method, Constr. Build. Mater. 68 (2014) 757-768, https://doi.org/10.1016/ j.conbuildmat.2014.07.010.

[41] R. Nogueira, A.P. Ferreira Pinto, A. Gomes, A. Bogas, Prediction of compressive strength for heterogeneous mortars from drilling resistance data, Int. J. Archit. Heritage (2018), https://doi.org/10.1080/15583058.2018.1547800.

[42] T.F. Dumitrescu, G.L.A. Pesce, R.J. Ball, Optimization of drilling resistance measurement (DRM) user-controlled variables, Mater. Struct. 50 (2017) 243. https://link.springer.com/article/10.1617/s11527-017-1113-8.

[43] K.E. Alyamac, J. Olek, The use of drilling tests to assess the strength of building materials: review of existing methods and a proposed new technique, in: Proceeding of SMAR 2017 - Fourth Conference on Smart Monitoring, Assessment and Rehabilitation of Civil structures, Zurich/Switzerland, 2017.

[44] www.sintwww.sintechnology.com.

[45] UNI EN 459-1, Building lime - Part 1: Definitions, specifications and conformity criteria, 2015.

[46] UNI EN 13139, Aggregates for mortar, 2013.

[47] UNI EN 1015-11, Methods of test for mortar for masonry - Part 11: Determination of flexural and compressive strength of hardened mortar, 2007.

[48] D.C. Montgomery, G.C. Runger, N.F. Hubele, Engineering Statistics, EGEA, Milano, 2009. ISBN: 88-238-2037-5. 